\title{
Use It or Lose It: Efficiency Gains from Wealth Taxation
}

\author{
Fatih Guvenen* Gueorgui Kambourov ${ }^{\dagger} \quad$ Burhan Kuruscu ${ }^{\ddagger}$ \\ Sergio Ocampo-Diaz ${ }^{\S}$ Daphne Chen $₫$
}

February 15, 2017

\section{Preliminary and Incomplete. Please do not distribute.}

\begin{abstract}
This paper studies the quantitative implications of wealth taxation (as opposed to capital income taxation) in an incomplete markets model with return rate heterogeneity across individuals. The rate of return heterogeneity arises from the fact that some individuals have better entrepreneurial skills than others, allowing them to obtain a higher return on their wealth. With such heterogeneity, capital income and wealth taxes have different efficiency and distributional implications. Under capital income taxation, entrepreneurs who are more productive and, as a result, generate more income pay higher taxes. Under wealth taxation, on the other hand, entrepreneurs who have similar wealth levels pay similar taxes regardless of their productivity. Thus, in this environment, the tax burden shifts from productive entrepreneurs to unproductive ones if the capital income tax were replaced with a wealth tax. This reallocation increases aggregate productivity. Second, and at the same time, it increases wealth inequality in the population. To provide a quantitative assessment of these different effects, we build and simulate an overlapping generations model with individual-specific returns on capital income and with idiosyncratic shocks to labor income. Our results indicate that switching from a capital income tax to a wealth tax increases welfare by almost $8 \%$ through better allocation of capital. We also study optimal taxation in this environment and find that, relative to the benchmark, the optimal wealth tax increases welfare by $9.6 \%$ while the optimal capital income tax increases it by $6.3 \%$.
\end{abstract}

*University of Minnesota, FRB of Minneapolis, and NBER; guvenen@umn. edu; www. fguvenen.com

${ }^{\dagger}$ Department of Economics, University of Toronto, 150 St. George St., Toronto ON, M5S 3G7, Canada; g. kambourov@utoronto.ca.

${ }^{\ddagger}$ Department of Economics, University of Toronto, 150 St. George St., Toronto ON, M5S 3G7, Canada; burhan.kuruscu@utoronto.ca.

$\S$ University of Minnesota; ocamp020@umn.edu.

"Econ One 


\section{Introduction}

Capital taxation is an important revenue source for governments. For example, taxes levied on various types of capital accounted for $27 \%$ of the total tax revenues in the United States in 2011 and $23.2 \%$ of the tax revenues in the 28 European Union countries in 2006 (see Table I). These averages also mask large variation across countries: the revenue share ranged from a low of 15.5 for Sweden to $36.5 \%$ for neighboring Norway. Expressed as a fraction of GDP, the level is again high and varies significantly, from a low of $6.5 \%$ of GDP for Germany to 15.9 for Norway.

Given these large magnitudes and the obvious potential of capital taxes to distort optimal investment decisions, it is perhaps not surprising that a vast body of literature has focused on the most efficient and/or equitable ways to tax capital income. However, beyond the equity/efficiency trade-off another key aspect of the tax policy is the precise way to impose taxes on capital/wealth. For example, while many countries tax the income flow generated by capital, some countries have also taxed the stock of wealth regardless of the flow of income it generates (e.g. France, Netherlands, Norway, Denmark, Spain, and Switzerland). The question of taxing the stock versus the flow has received scant attention, partly because under the standard assumption of identical returns received by all investors capital income taxes and wealth taxes have identical (or very similar implications).

TABle I - Capital Income Taxes, Select OECD Countries

\begin{tabular}{lcc}
\hline \hline & \% of GDP & \% of taxes \\
\cline { 2 - 3 } USA & 8.0 & 27.0 \\
UK & 11.4 & 31.5 \\
France & 10.7 & 24.3 \\
Germany & 6.5 & 16.8 \\
Sweden & 7.5 & 15.5 \\
Norway & 15.9 & 36.5 \\
Luxembourg & 11.2 & 31.3 \\
EU-28 & 9.2 & 23.2 \\
\hline
\end{tabular}

Source: European Commission (2011, Table 54, year 2006) and OECD (2011, USA).

Recent empirical studies cast strong doubt on this assumption of identical returns 
by documenting large and persistent heterogeneity in returns, using clean and large administrative panel data sets that track millions of households over long periods of time (e.g., Fagereng et al (2015), and others reviewed in the next section). Furthermore, a new class of economic models of inequality have shown that the Pareto right tail of the wealth distribution cannot be generated by models where the source of risk is idiosyncratic labor income, whereas a model that incorporates return heterogeneity can generate the Pareto tail. Moreover, if the return heterogeneity is persistent over time, then these class of models also generate behavior consistent with the dynamic evolution of inequality over time.

In this paper, we study the optimal structure of the taxation of capital and, in particular, analyzes how taxing the income flow from capital (hereafter, "capital income tax") differs from taxing the stock of wealth (hereafter "wealth tax"). Our analysis is in the tradition of the Ramsey taxation literature and is conducted using a fully-specified and calibrated economic framework to provide a quantitative evaluation of the pros and cons of each policy.

Our analysis reveals three main conclusions, which we elaborate on in a moment: (i) a revenue-neutral switch from the current US tax system of capital income taxation to a flat wealth tax system increases average welfare significantly, (ii) when each policy is considered separately, a positive tax on the stock of wealth is optimal, whereas in most of the scenarios we consider a negative tax (or a subsidy) on capital income is optimal, and (iii) in addition to quantitative differences, the implications of a capital income tax and a wealth tax are also qualitatively the opposite of each other; in particular a wealth tax delivers efficiency gains but redistributional losses, which is the opposite of the effect of a capital income tax (efficiency loss but redistributional gains).

The specifics of the model we study are as follows. We study an overlapping generations economy inhabited by individuals who derive utility from consumption and leisure and die probabilistically. The key ingredient of the model is that each individual has an entrepreneurial skill that has a permanent fixed component, which differs from other individuals, and possibly (but not necessary) a stochastic component which evolves over the life cycle. This entrepreneurial skill is realized when the individual operates this individual-specific technology. Individuals can borrow from a bond market to invest in their "firm" over and above their own saved resources. The same bond market can also be used as a savings device, which will be optimal for individuals whose entrepreneurial skill (and hence private return) is very low. Individuals also face idiosyncratic labor income 
risk, borrowing constraints in the bond market, and other features, although we show that these additional details do not change the main conclusions of the paper. Finally, we also consider intergenerational links between parents and children through accidental bequests, and the transmission of entrepreneurial and labor market ability. These also turn out not to be too important.

With such rate of return heterogeneity, capital income and wealth taxes are no longer equivalent. Under capital income taxation, entrepreneurs who are more productive and, as a result, generate more income pay higher taxes. Under wealth taxation, on the other hand, entrepreneurs who have similar wealth levels pay similar taxes regardless of their productivity. In this environment, the tax burden would shift from productive entrepreneurs to unproductive ones if capital income tax were replaced with wealth tax. Since children of very successful entrepreneurs often inherit large amounts of wealth but may not be able to work it as efficiently, society can reallocate wealth from less productive children to those with better uses of capital by switching to wealth tax. This reallocation has a first order effect on aggregate productivity. However, since on average more productive entrepreneurs have more wealth, wealth inequality should increase after this switch. This discussion should reveal that these two forms of taxation have different distributional and efficiency implications when people earn different rates of returns on wealth. Relative to the capital income tax, wealth tax generates efficiency gains but distributional losses. Our framework allows us to study the structure and level of optimal taxes on wealth taking into account these efficiency and inequality trade-offs. Moreover, modeling investor heterogeneity in the study of optimal taxation allows us to quantify who gains and who loses from different forms of taxation and brings us one step closer to the political economy aspect.

To provide a quantitative assessment of these different effects and the optimal level of wealth taxation, we build and simulate an overlapping generations model with individualspecific returns on capital and idiosyncratic shocks to labor income. Entrepreneurial ability (or rate of return) is allowed to vary both within a generation and across generations (from parent to child). The key exercise we conduct is to consider an economy calibrated to the US data and implement a revenue-neutral tax reform that replaces capital income tax with wealth tax. Our results indicate that switching from a capital income tax to a wealth tax has large welfare gains - welfare increases by almost $8 \%$ in the tax reform through better allocation of capital. We also study optimal taxation in this environment and find that, relative to the benchmark, the optimal wealth tax 
increases welfare by $9.6 \%$ while the optimal capital income tax increases it by only $6.3 \%$

One of the advantages of our framework is that, with rate of return heterogeneity, it generates the high wealth concentration observed in the data. In the U.S., for example, the richest top $1 \%$ of all households owns $34 \%$ of the total net worth (Diaz-Gimenez et al. (2011)). Given this large wealth inequality, it is important for studies of wealth taxation to be able to account for the wealth inequality. Thus, we view incorporating rate of return heterogeneity in the study of optimal taxation as an important step. In fact, the theoretical and quantitative literature on wealth inequality has demonstrated that rate of return heterogeneity is central for understanding this high wealth concentration. Following the influential works of Huggett (1993) and Aiyagari (1994), several papers have studied models with incomplete financial markets and uninsurable labor income risk in order to understand the high wealth inequality (Among others see for example Krusell and Smith (1998) and Storesletten et al. (2001)). A common finding from this literature is that labor income risk and incomplete markets fall short of generating the high concentration of wealth observed in the data. Castañeda et al. (2003) do significantly better in matching the high Gini coefficient for wealth. However, even this most successful attempt generates $14.7 \%$ wealth holdings in the hands of the top $1 \%$. A parallel literature has investigated models with heterogeneity in entrepreneurial ability and capital income risk (Quadrini (2000); Cagetti and De Nardi (2009, 2006); Benhabib et al. (2011, 2013, 2014) ). These papers have shown that incorporating rate of return heterogeneity goes a long way in accounting for the high concentration of wealth in the hands of the few. Two of these papers also study fiscal policy. Cagetti and De Nardi (2009) evaluate the effect of eliminating estate taxation and Benhabib et al. (2011) study the effect of capital income and estate taxes on wealth inequality. Neither of these papers however, analyzes the differences between capital income and wealth taxes, nor studies optimal capital taxation as we do in this paper.

\section{Literature Review.}

The earlier work on capital income taxation date back to the famous Chamley-Judd result, which established that under a general set of conditions the optimal tax on capital is zero, assuming that market are complete and people are infinitely lived (Judd (1985); Chamley (1986)). Subsequent quantitative analyses by Lucas (1990), Atkeson et al. (1999), and Jones et al. (1993) have shown that even in richer environments the optimal

level turns out to be very close to zero. A parallel literature relaxed these assumptions 
(Hubbard et al. (1986); Aiyagari (1995); Imrohoroglu (1998); Erosa and Gervais (2002); Garriga (2003); Conesa et al. (2009); Kitao (2010)). By incorporating more realistic features such as incomplete financial markets and/or finitely lived agents, this recent literature has shown that it is in fact desirable to tax capital and the optimal capital tax can be large. In a recent study, Werning (2014) has reevaluated the results in Judd (1985) and Chamley (1986). He has shown that zero tax result is achieved in very special cases and, when it is achieved, very slowly after taxing capital at very high rates early on. Thus, he concludes that zero capital taxation result is not practical.

The idea of wealth taxes has also been recently proposed by Thomas Piketty in his influential book, Capital in the Twenty-First Century (Piketty (2014)). Piketty proposes using a combination of capital income and wealth taxes to balance these efficiency and inequality tradeoffs. Piketty mostly focuses on equity considerations, but also describes the efficiency gain benefits of the use-it-or-lose-it mechanism. However, he does not provide a formal analysis of it. Our paper provides a full-blown framework to find the structure of optimal taxes on wealth, including the tax base, the level, and progressivity of the optimal tax system taking these efficiency-inequality trade-offs into consideration.

Several other papers have also used frameworks with entrepreneurial or firm heterogeneity to address different questions. Buera et al. (2011) uses a framework with entrepreneurial heterogeneity, very similar to ours, to explain the aggregate productivity and financial development across countries. Gabaix (2011) show that idiosyncratic shocks to firm productivities can generate aggregate fluctuations.

Several papers have applied the Mirleesian approach to optimal taxation by studying the problem of a planner in an environment where economic agents have some incentive issues and implementing the planner's allocations with tax policy (Among others, notable examples of this literature are Golosov et al. (2003) and Kocherlakota (2005)). Shourideh (2012) applies the same approach to study optimal taxes in an environment with rate of return heterogeneity. However, this paper neither distinguishes capital income and wealth taxes, nor goes beyond a theoretical analysis in a simple framework. In our paper, on the other hand, we construct a much richer framework embedded in data that we use for quantitative analysis. 


\section{Simple Example}

Consider two entrepreneurs, each with $\$ 1000$ of wealth, who differ in the rate of return they are able to generate on their capital. The low ability entrepreneur earns an annual return of $r_{1}=0 \%$, whereas the second one earns $r_{2}=20 \%$. There is a government expenditure of $G=\$ 50$ that needs to be financed with tax revenues. If the government taxes the capital income, the required tax rate is $25 \%$ on income and is paid entirely by the second entrepreneur. Thus, the after-tax return of each entrepreneur is $0 \%$ and $15 \%$. By the end of the period, the first entrepreneur's wealth has not changed whereas the second entrepreneur experienced a rise from $\$ 1000$ to $\$ 1150$ after paying his taxes. Now suppose that the government raises the same revenue by imposing a flat tax on the stock of wealth. Now the base of taxation is broader because both individuals have a stock of wealth, for a total of $\$ 2200$ at the end of the period. The tax rate on wealth is $50 / 2200 \approx 2.27 \%$. Out of the $\$ 50$, approximately $\$ 23$ is paid by the first entrepreneur and $\$ 27$ is paid by the second. The after-tax rate of return is, respectively, $(\$ 0-\$ 23) / \$ 1000 \approx-2.3 \%$ and $(\$ 200-\$ 27) / \$ 1000 \approx 17.3 \%$. Notice that the dispersion in after-tax returns is higher with wealth taxes and the end of period wealth inequality is also higher: $1173 / 977$ versus $1150 / 1000=1.15$ before. But what happens most crucially is that at the end of the period, the entrepreneur who is better at investing owns a larger fraction of aggregate wealth $54.6 \%$ vs $53.5 \%$. So, wealth taxation has two potential effects. First, capital is allocated (mechanically) to the more productive agent. And second, if this one period example was repeated over many years and if savings rates respond to changes in returns, this could further increase reallocation of capital to the more productive agent. Thus, the more productive entrepreneur would own a larger portion of aggregate wealth due to higher returns, which would lead to higher output. However, note that wealth inequality is higher under wealth tax and it should increase over time if we switch from capital income tax to wealth tax. This discussion reveals that these two forms of taxation have different distributional and efficiency implications when people earn different rates of returns on wealth. Relative to the capital income tax, wealth tax generates efficiency gains but distributional losses. 
TABle II - Capital Income Tax vs. Wealth Tax

\begin{tabular}{cccccc}
\hline & \multicolumn{2}{c}{ Capital Income Tax } & & \multicolumn{2}{c}{ Wealth Tax } \\
\cline { 2 - 3 } \cline { 5 - 6 } & $r_{1}=0 \%$ & $r_{2}=20 \%$ & & $r_{1}=0 \%$ & $r_{2}=20 \%$ \\
\hline Wealth & 1000 & 1000 & & 1000 & 1000 \\
Pre-tax Income & 0 & 200 & & 0 & 200 \\
\hline Tax rate & \multicolumn{2}{c}{$\tau_{k}=\frac{50}{200}=0.25$} & & $\tau_{a}=\frac{50}{2200}=2.27 \%$ \\
Tax liability & 0 & 50 & & $1000 \frac{50}{2200} \approx 23$ & $1200 \frac{50}{2200} \approx 27$ \\
After-tax rate of return & 0 & $\frac{200-50}{1000}=15 \%$ & & $-\frac{23}{1000}=-2.3 \%$ & $\frac{200-27}{1000}=17.3 \%$ \\
After-tax Wealth Ratio & $W_{2} / W_{1}=1150 / 1000=1.15$ & & $W_{2} / W_{1}=1173 / 977 \approx 1.20$ \\
\hline
\end{tabular}

\section{Quantitative Model}

The economy is populated by overlapping generations of finitely lived individuals (households), a final goods producer that buys intermediate goods and labor services from households, and a government that levies taxes for financing an exogenously given expenditure stream.

\subsection{Environment}

Individuals (households) face mortality risk and can live up to a maximum of $H$ years. Let $\phi_{h}$ be the unconditional probability of survival up to age $h$, where $\phi_{1}=1$. Let $s_{h} \equiv \phi_{h} / \phi_{h+1}$ be the conditional probability of surviving from age $h-1$ to $h$. When an individual dies, it is replaced by an offspring that inherits its wealth.

Each individual is a worker-entrepreneur who supplies labor in the labor market and produces a differentiated intermediate good by using capital. The individual has access to her own wealth as well as a financial market for supplying capital for her entrepreneurial activities. In the financial market the individual faces a financial constraint. Individuals retire from working at age $R(1<R \leq H)$, but they retain their entrepreneurial activity until they die. 
Preferences. Individual preferences are given by:

$$
\mathbb{E}_{0}\left(\sum_{h=1}^{H} \beta^{h-1} \phi_{h} u\left(c_{h}, \ell_{h}\right)\right)
$$

where $c_{h}$ is consumption at age $h$ while $\ell_{h}$ is leisure at age $h{ }^{1}$

Labor market productivity. At a given age individuals differ in their labor market ability, $y_{i h}$, which consists of three components

$$
\log y_{i h}=\underbrace{\theta_{i}}_{\text {permanent }}+\underbrace{\kappa_{h}}_{\text {lifecycle }}+\underbrace{e_{i h}}_{\operatorname{AR}(1)}
$$

where $\theta_{i}$ is an individual fixed effect, $\kappa_{h}$ is a life-cycle component that is common to all individuals and $e_{i h}$ follows an $\mathrm{AR}(1)$ process during working years $(h<R)$ :

$$
e_{i h}=\rho_{e} e_{i, h-1}+\epsilon_{e}
$$

where $\epsilon_{e}$ is an i.i.d. shock with mean zero and variance $\sigma_{\epsilon_{e}}^{2}$. When an individual dies at age $h$, she is replaced by her offspring with $h=1$ that inherits her wealth. Individualspecific labor market ability $\theta$ is imperfectly inherited from parents:

$$
\theta^{\text {child }}=\rho_{\theta} \theta^{\text {parent }}+\epsilon_{\theta}
$$

where $\epsilon_{\theta}$ is an i.i.d. shock with mean zero and variance $\sigma_{\epsilon_{\theta}}^{2}$.

Given the wage rate $w$ per efficiency units of labor, the individual's labor income is given by $w y_{i h} n$ where $n$ is the hours supplied in the market.

Entrepreneurial process. The key feature of the model is heterogeneity in (average) return to capital, without which capital income taxes and wealth taxes can have identical effects. $^{2}$ Individual $i$ owns the product line $i$ and produces $x_{i h}$ units of intermediate good $i$ according to

$$
x_{i h}=z_{i h} k_{i h},
$$

\footnotetext{
${ }^{1}$ There is no bequest motive. We consider a bequest motive in one of the extensions of the paper.

${ }^{2}$ Notice that wealth and capital income taxes can have different implications even when marginal returns are equal across individuals, if average returns are different. This will be the case in versions of our baseline model below. But to see a simpler example with linear returns - so that marginal and average returns are equal - suppose that all individuals earn the same average rate of return $r$ on wealth. In this case, consider the budget constraint of a household under two tax systems (capital income tax
} 
where $z_{i h}$ is the individual $i$ 's entrepreneurial ability and $k_{i h}$ is capital. Entrepreneurial ability $z_{i h}$ has a permanent and a stochastic component. As a result,

$$
z_{i h}=f\left(z_{i}^{p}, z_{i h}^{s}\right)
$$

where $z_{i}^{p}$ captures permanent differences in entrepreneurial ability while $z_{i h}^{s}$ captures variations over the life-cycle. $z_{i h}^{s}$ is governed by the transition matrix $\Pi_{z}$ while a newborn inherits $z_{i}^{p}$ imperfectly from her parent:

$$
\log \left(z_{\text {child }}^{p}\right)=\rho_{z} \log \left(z_{\text {parent }}^{p}\right)+\varepsilon_{z}
$$

where $\epsilon_{z}$ is an i.i.d. shock with mean zero and variance $\sigma_{\epsilon_{z}}^{2}$. Due to the imperfect correlation between the parent's and child's ability, some children end up with large amount of wealth but with low entrepreneurial ability. Similarly, some children with little assets at the beginning of their life have high entrepreneurial abilities.

In particular, we assume that $z_{i h}^{s} \in\{H, L, 0\}$ such that

$$
z_{i h}=f\left(z_{i}^{p}, z_{i h}^{s}\right)= \begin{cases}\left(z_{i}^{p}\right)^{\omega} & \text { if } z_{i h}^{s}=H \quad \text { where } \omega>1 \\ z_{i}^{p} & \text { if } z_{i h}^{s}=L \\ 0 & \text { if } z_{i h}^{s}=0\end{cases}
$$

and wealth tax) ignoring other taxes for simplicity:

$$
\begin{aligned}
& c+a^{\prime}=\left[1+r\left(1-\tau_{k}\right)\right] a+w n \quad \text { when capital income is taxed at rate } \tau_{k} \\
& c+a^{\prime}=(1+r)\left(1-\tau_{a}\right) a+w n \quad \text { when wealth stock is taxed at rate } \tau_{a},
\end{aligned}
$$

where $a$ is wealth, $r$ is the interest rate, and $w n$ is the labor income. Suppose the government has to finance the same amount of expenditures $G$ in both cases. Then,

$$
G=\tau_{k} r \int_{a} a \Gamma(d a)=\tau_{a}(1+r) \int_{a} a \Gamma(d a),
$$

where $\Gamma(a)$ is the distribution of agents over wealth. The government budget constraint implies that

$$
\tau_{k} r=\tau_{a}(1+r) \Rightarrow \tau_{a}=\frac{r \tau_{k}}{1+r}
$$

If we insert $\tau_{a}$ into the after-tax return in the wealth tax we obtain

$$
(1+r)\left(1-\tau_{a}\right)=(1+r)\left(1-\frac{r \tau_{k}}{1+r}\right)=1+r\left(1-\tau_{k}\right)
$$

Therefore, the budget constraint of the household under two tax systems are the same, so the decision rules will be the same. 
with transition matrix

$$
\Pi_{z}=\left[\begin{array}{ccc}
1-p_{1}-p_{2} & p_{1} & p_{2} \\
0 & 1-p_{2} & p_{2} \\
0 & 0 & 1
\end{array}\right]
$$

Finally, individuals whose permanent ability is above the median permanent ability-i.e., $z^{p}>z_{\text {med }}^{p}=1$ - start life in state $z_{i h}^{s}=H$ while the rest start in state $z_{i h}^{s}=L$.

Financial markets. There are financial market frictions that restrict the extent to which individuals can borrow to invest in their business. In particular, an individual with assets $a$ faces a financial constraint

$$
k \leq \vartheta\left(z_{i h}\right) a,
$$

where $\vartheta\left(z_{i h}\right) \in[1, \infty]$. The dependence of $\vartheta$ on $z_{i h}$ is to allow for the fact that more highly productive agents could potentially borrow more with the same level of capital. This is a feature that we will have in the baseline calibration and will also consider the case with $\vartheta\left(z_{i h}\right)=\bar{\vartheta}$. When $\vartheta=1$ the financial constraint is extreme since the individual can only use her own assets in production. When $\vartheta=\infty$ there is no longer a financial constraint since there is no longer a restriction on the amount that an individual can borrow.

Taxation. Individuals pay a proportional consumption tax, $\tau_{c}$, and a proportional capital income $\operatorname{tax} \tau_{k}$. The individual also pays a labor income tax, where for a labor income of $w y_{i h} n$ the after-tax labor income is

$$
\left(1-\tau_{l}\right)\left(w y_{i h} n\right)^{\psi}
$$

where the parameter $\psi$ controls the progressivity of the labor income tax: when $\psi=1$ the labor income tax is proportional at the level $\tau_{l}$ and the progressivity increases with $\psi$.

In our main experiment we will study a revenue-neutral switch to a tax system where the government taxes the individual's wealth stock at the proportional rate $\tau_{a}$. We will also discuss the case where the proportional wealth tax $\tau_{a}$ is imposed only for wealth above a certain threshold level, inducing progressivity in the wealth tax. 
Social security. When an agent retires at age $R$, she starts receiving social security income $y^{R}(\theta)$ that depends on her type $\theta$ in the following way:

$$
y^{R}(\theta, e)=\Phi(\theta, e) \bar{E}
$$

where $\Phi$ is the agent's replacement ratio, a function that depends on the agent's permanent type $\theta$ and the last transitory shock to labor productivity, and $\bar{E}$ which corresponds to the average earnings of the working population in the economy.

Final Goods Producer. The final goods producer behaves competitively and uses labor and intermediate goods in the production of the final good:

$$
Y=Q^{\alpha} L^{1-\alpha}
$$

where $Q$ is the intermediate good aggregator given by

$$
Q=\left(\int_{i} x_{i}^{\mu}\right)^{1 / \mu}
$$

The problem of the final good producer can be written as

$$
\max _{\left\{x_{i}\right\}, L}\left(\int_{i} x_{i}^{\mu}\right)^{\alpha / \mu} L^{1-\alpha}-\int_{i} p_{i} x_{i}-w L,
$$

where $p_{i}$ is the price of the intermediate good $i$ and $w$ is the wage rate. Taking the first order conditions, we obtain the following pricing function for intermediate good $i$

$$
p_{i}\left(x_{i}\right)=\alpha x_{i}^{\mu-1} Q^{\alpha-\mu} L^{1-\alpha},
$$

and the wage rate

$$
w=(1-\alpha) Q^{\alpha} L^{-\alpha} .
$$

Note that the price of the intermediate good $i$ depends only on the quantity of intermediate good. Therefore, we can drop $i$ in the price and write the price as only a function of quantity $x$

$$
p(x)=\alpha x^{\mu-1} Q^{\alpha-\mu} L^{1-\alpha} .
$$




\subsection{Individual's problem}

For clarity of notation, in this subsection we suppress the individual subscript $i$. Note that the production problem of each agent is static in nature and can be solved in isolation of the other decisions the agent takes. In particular, the agent will maximize the profits coming from the entrepreneurial activity by choosing an optimal capital demand:

$$
\begin{aligned}
& \pi(a, z)=\max _{k \leq \vartheta(z) a}\{p(z k) z k-(r+\delta) k\} \\
& \text { s.t. } p(z k)=P(z k)^{\mu-1},
\end{aligned}
$$

where $z=f\left(z^{p}, z^{s}\right)$ and $P=\alpha Q^{\alpha-\mu} L^{1-\alpha}$. The decision of the individual is then:

$$
k(a, z)=\min \left\{\left(\frac{\mu P z^{\mu}}{r+\delta}\right)^{\frac{1}{1-\mu}}, \vartheta(z) a\right\},
$$

which yields

$$
\pi(a, z)=\left\{\begin{array}{ll}
P(z \vartheta(z) a)^{\mu}-(r+\delta) \vartheta(z) a & \text { if } k(a, z)=\vartheta(z) a \\
(1-\mu) P z^{\mu}\left(\frac{\mu P z^{\mu}}{r+\delta}\right)^{\frac{\mu}{1-\mu}} & \text { if } k(a, z)<\vartheta(z) a
\end{array} .\right.
$$

The household's after-tax non-labor income, $Y\left(a, z, \tau_{k}, \tau_{a}\right)$, is given by after-tax profits from their firm and interest payments obtained from the financial market:

$$
Y\left(a, z, \tau_{k}, \tau_{a}\right)=\left[a+(\pi(a, z)+r a)\left(1-\tau_{k}\right)\right]\left(1-\tau_{a}\right)
$$

The individual's problem then is given by:

$$
\begin{aligned}
& V_{h}(a, \mathbf{S})=\max _{c, n, a^{\prime}} u(c, 1-n)+\beta s_{h+1} E\left[V_{h+1}\left(a^{\prime}, \mathbf{S}^{\prime}\right) \mid \mathbf{S}\right] \\
& \text { s.t. }\left(1+\tau_{c}\right) c+a^{\prime}=Y\left(a, f\left(z^{p}, z^{s}\right), \tau_{k}, \tau_{a}\right)+y^{W}(\theta, e) \\
& a^{\prime} \geq 0,
\end{aligned}
$$

where $\mathbf{S}=\left(z^{p}, z^{s}, \theta, e\right)$ is the vector of exogenous states of an individual and

$$
y^{W}(\theta, e)=\left\{\begin{array}{ll}
\left(1-\tau_{l}\right)\left(w y_{h} n\right)^{\psi} & \text { if } h<R \\
y^{R}(\theta, e) & \text { if } h \geq R .
\end{array} \quad \text { where } \log y_{h}=\theta+\kappa_{h}+e\right.
$$


We assume that $e_{h}=e_{h-1}$ for $h \geq R$, thus the retirement income is essentially conditioned on the earnings shock in period $R-1$.

\subsection{Government}

The government taxes capital income, labor income, and consumption in order to finance government expenditures $G$ and social security payments. For future reference let

$$
S S C=\sum_{h \geq R, a, \mathbf{S}} y^{R}(\theta, e) \Gamma(h, a, \mathbf{S})
$$

be the total social security payments. Above $\Gamma$ is the stationary distribution of agents over all possible states.

To characterize $y^{R}(\theta, e)$ we define:

$$
\bar{E}=\frac{w \bar{N}}{I_{1}^{R}}
$$

where $w$ is the economy wide wage rate (per efficiency units), $I_{1}^{R} \leq 1$ is the measure of agents in working age, and $\bar{N}$ is the total number of effective hours worked in the economy:

$$
\bar{N}=\sum_{h<R, a, \mathbf{S}} y_{h}(\theta, e) n_{h}(s) \Gamma(h, a, \mathbf{S})
$$

Note that the summation is taken over efficiency units $y_{h}$. The replacement ratio is progressive and satisfies:

$$
\Phi(\theta, e)= \begin{cases}0.9 \frac{y_{1}^{R}(\theta, e)}{\bar{y}_{1}^{R}} & \text { if } \frac{y_{1}^{R}(\theta, e)}{\bar{y}_{1}^{R}} \leq 0.3 \\ 0.27+0.32\left(\frac{y_{1}^{R}(\theta, e)}{\bar{y}_{1}^{R}}-0.3\right) & \text { if } 0.3<\frac{y_{1}^{R}(\theta, e)}{\bar{y}_{1}^{R}} \leq 2 \\ 0.91+0.15\left(\frac{y_{1}^{R}(\theta, e)}{\bar{y}_{1}^{R}}-2\right) & \text { if } 2<\frac{y_{1}^{R}(\theta, e)}{\bar{y}_{1}^{R}} \leq 4.1 \\ 1.1 & \text { if } 4.1<\frac{y_{1}^{R}(\theta, e)}{\bar{y}_{1}^{R}}\end{cases}
$$

where $y_{1}^{R}(\theta, e)$ is the average efficiency units that an agent of type $\theta$ gets conditional on having a given $e_{R}=e$.

$$
y_{1}^{R}\left(\theta, e_{R}\right)=\frac{1}{R} \sum_{h<R, a, \mathbf{S}} \int y_{h}(\theta, e) \Gamma(h, a, \mathbf{S})
$$

the integral is taken with respect to the stationary distribution of agents by age and is 
taken over all possible asset holdings, types $z$, and histories of $e$ such that $e_{R}$ is the one given in the left hand side. Finally $\bar{y}_{1}^{R}$ is the average of $y_{1}^{R}(\theta, e)$ across $\theta$ and $e$.

\subsection{Equilibrium}

Let $c_{h}(a, \mathbf{S}), n_{h}(a, \mathbf{S})$ and $a_{h+1}(a, \mathbf{S})$ denote the optimal decision rules and $\Gamma(h, a, \mathbf{S})$ be the stationary distribution of agents. A competitive equilibrium is given by the following conditions:

1. Consumer's maximize given $p(x), w, r$ and taxes.

2. The solution to the final goods producer gives pricing function $p(x)$ and wage rate $w$.

3. $Q=\left(\sum_{h, a, \mathbf{S}}(z a)^{\mu} \Gamma(h, a, \mathbf{S})\right)^{1 / \mu}$ and $L=\sum_{h, a, \mathbf{S}} y_{h} n_{h}(a, \mathbf{S}) \Gamma(h, a, \mathbf{S})$, where $\log y_{h}=$ $\theta+\kappa_{h}+e$.

4. The government budget balances. We will compare the following two alternatives:

(a) Taxing capital and labor income, in which case the government's budget becomes

$$
\begin{aligned}
G+S S C & =\tau_{k} \sum_{h, a, \mathbf{S}}(\pi(a, z)+r a) \Gamma(h, a, \mathbf{S}) \\
& +\tau_{L} \sum_{h, a, \mathbf{S}}\left(w y_{h} n_{h}(a, \mathbf{S})\right) \Gamma(h, a, \mathbf{S}) \\
& +\tau_{c} \sum_{h, a, \mathbf{S}} c_{h}(a, \mathbf{S}) \Gamma(h, a, \mathbf{S})
\end{aligned}
$$

where

$$
S S C=\sum_{h \geq R, a, \mathbf{S}} y^{R}(\theta, e) \Gamma(h, a, \mathbf{S})
$$

(b) Taxing wealth stock and labor income, in which case the government's budget 
becomes

$$
\begin{aligned}
G+S S C & =\tau_{a} \sum_{h, a, \mathbf{S}}((1+r) a+\pi(a, z)) \Gamma(h, a, \mathbf{S}) \\
& +\tau_{L} \sum_{h, a, \mathbf{S}}\left(w y_{h} n_{h}(a, \mathbf{S})\right) \Gamma(h, a, \mathbf{S}) \\
& +\tau_{c} \sum_{h, a, \mathbf{S}} c_{h}(a, \mathbf{S}) \Gamma(h, a, \mathbf{S})
\end{aligned}
$$

5. The bond market clears:

$$
0=\sum_{h, a, \mathbf{S}}(a-k(a, z)) \Gamma(h, a, \mathbf{S})
$$

\section{Quantitative Analysis: Tax Reform}

\subsection{Model Parameterization}

The benchmark model is calibrated to US data. The model period is one year.

Government Policy. The benchmark economy has a proportional capital income tax $\tau_{k}$, a proportional labor earnings tax determined by $\tau_{l}$, and a proportional consumption $\operatorname{tax} \tau_{c}$. Using the results in McDaniel (2007), we calibrate a capital income tax $\tau_{k}$ of $25 \%$, a labor income tax of $22.4 \%$, and a consumption tax of $7.5 \%$.

Demographics. Individuals enter the economy at age 20 and can live up to 80 years (so the maximum real life age is 100). They retire at age $R=46$, which is 66 years old. The conditional survival probabilities from age $h$ to $h+1$ are taken from Bell and Miller (2002) for the US data.

Preferences. Individuals value consumption $c$ and leisure $\ell$. The utility function takes the following form

$$
u(c, \ell)=\frac{\left(c^{\gamma} \ell^{1-\gamma}\right)^{1-\sigma}}{1-\sigma} .
$$

We calibrate $\beta=0.9475$ to generate a wealth-to-output ratio of 3 in the stationary equilibrium. The leisure parameter $\gamma=0.46$ is calibrated to match an average hours of work of 0.4 for the working age population, i.e. ages 25 to 60, in equilibrium. 
Labor market efficiency. The parameters governing the labor market efficiency over the life cycle are taken from the literature that estimates earnings processes. We set the persistence of the stochastic component of the labor income $\rho_{e}$ to 0.9 , which is in the middle of the empirical estimates. ${ }^{3}$ The standard deviation of the innovation is 0.2 , which implies that the variance of the stochastic component is 0.22 . The life-cycle component $\kappa_{h}$ is chosen to deliver a 50 percent rise in 30 years (from age 21 to 51 , which is model age 1 to 31$)$ to the peak. Therefore, it is assumed to take a quadratic polynomial form $\kappa_{i h}=\frac{60(h-1)-(h-1)^{2}}{1800}$. We assume that the correlation between the parent's and the child's permanent component $\rho_{\lambda}$ is 0.5 . The standard deviation of the innovation $\epsilon_{\lambda}$ is chosen so that the cross-sectional standard deviation of log labor earnings is 0.80 , which implies that $\sigma_{\epsilon_{\theta}}=0.305 .^{4}$

Entrepreneurial skills. The intergenerational process in entrepreneurial skill is governed by the parameters $\rho_{z}$ and $\sigma_{z}$, and they are calibrated in order to match the following wealth distribution statistics: the top 1 percent in the wealth distribution hold 35 percent of the total wealth while the top 10 percent hold 75 percent.

Production. For the final good producer, the intermediate goods aggregator share $\alpha$ is set to 0.40 , while the labor share $1-\alpha$ is set to 0.60 . For the intermediate goods producer, we fix the curvature parameter $\mu$ to be 0.9 . We will provide robustness checks on its value.

Financial constraint. We allow firms with higher productivity to borrow more. In particular, we choose

$$
\vartheta\left(z_{i}^{p}\right)=1+1.5(i-1) / 8 \text { for } i=1, \ldots, 9 \text {. }
$$

Note that we have 9 grid points for the permanent component of $z$.

Table III summarizes the set of parameters, which we calibrate independently. Table IV summarizes the set of parameters that are calibrated jointly in equilibrium to match the moments as shown in Table $\mathrm{V}$.

\footnotetext{
${ }^{3}$ See Guvenen (2007) and others.

${ }^{4}$ The cross-sectional standard deviation of log labor earnings is computed for individuals between 25 and 60 years old, who work at least $5.5 \%$ of their discretionary time, which corresponds to onequarter (13 weeks) of part-time (20 hours per week) employment relative to an annual time endowment of $365 \times 12$ hours.
} 
TABle III - Benchmark Parameters Calibrated Independently

\begin{tabular}{lcc}
\hline \hline Parameter & & Value \\
\hline Capital income tax rate & $\tau_{k}$ & 0.25 \\
Labor income tax rate & $\tau_{L}$ & 0.224 \\
Consumption tax rate & $\tau_{c}$ & 0.075 \\
Exponent of labor tax function (baseline) & $\psi$ & 0.00 \\
Wealth tax rate & $\tau_{a}$ & 0.00 \\
\hline Autocorrelation for idiosyncratic labor efficiency & $\rho_{e}$ & 0.9 \\
Std. for idiosyncratic labor efficiency & $\sigma_{\epsilon_{e}}$ & 0.2 \\
Interg. correlation of labor fixed effect & $\rho_{\theta}$ & 0.5 \\
Intermediate goods aggregate share in production & $\alpha$ & 0.4 \\
Curvature parameter of CES production func. & $\mu$ & 0.9 \\
Depreciation rate & $\delta$ & 0.05 \\
Curvature of utility function & $\sigma$ & 4.0 \\
\hline Maximum age & $H$ & 81 \\
Retirement age & $R$ & 45 \\
Survival probabilities & $\phi_{h}$ Bell and Miller (2002) \\
\hline
\end{tabular}

TABLE IV - Benchmark Parameters Calibrated Jointly in Equilibrium

\begin{tabular}{lll}
\hline \hline Parameter & & Value \\
\hline Discount factor & $\beta$ & 0.9475 \\
Consumption share in utility & $\gamma$ & 0.460 \\
Persistence of entrepreneurial ability & $\rho_{z}$ & 0.10 \\
Std. dev. of entrepreneurial ability & $\sigma_{\varepsilon_{z}}$ & 0.072 \\
Std. dev. of individual fixed effect & $\sigma_{\theta}$ & 0.305 \\
\hline
\end{tabular}

TABle V - Data and Benchmark Model Moments

\begin{tabular}{lcc}
\hline \hline Target & Data & Benchmark \\
\hline Wealth-output ratio & 3.00 & 3.00 \\
Top 1 percent wealth & 0.357 & 0.357 \\
Top 10 percent wealth & 0.75 & $0.66 *$ not targeted \\
Average Hours & 0.40 & 0.40 \\
Std of log earnings & 0.80 & 0.80 \\
\hline
\end{tabular}

\subsection{Performance of the benchmark model}


Table VI - Distribution of Agents by Productivity Types

\begin{tabular}{ccccccccccr}
\hline \hline & \multicolumn{10}{c}{ Permanent Productivity } \\
\cline { 2 - 11 } Trans. Prod & $z_{1}$ & $z_{2}$ & $z_{3}$ & $z_{4}$ & \multicolumn{1}{c}{$z_{5}$} & $z_{6}$ & $z_{7}$ & $z_{8}$ & $z_{9}$ & Total \\
\cline { 2 - 11 }$x_{1}$ & 0.29 & 2.82 & 11.24 & 17.80 & 5.09 & 1.28 & 0.13 & 0.005 & 0.0001 & 38.64 \\
$x_{2}$ & 0 & 0 & 0 & 0 & 6.15 & 1.54 & 0.15 & 0.006 & 0.0001 & 7.85 \\
$x_{3}$ & 0.33 & 3.25 & 12.93 & 20.48 & 12.93 & 3.25 & 0.32 & 0.012 & 0.0002 & 53.51 \\
Total & 0.62 & 6.07 & 24.17 & 38.28 & 24.17 & 6.07 & 0.60 & 0.023 & 0.0003 & 100.00 \\
\hline
\end{tabular}

TABLE VII - Statistics of Benchmark model vs Tax Reform

\begin{tabular}{lc|c} 
& & \\
\hline \hline & US Data & Benchmark \\
\hline Top 1\% & 0.357 & 0.36 \\
Top 10\% & 0.75 & 0.66 \\
Top 20\% & XX & 0.81 \\
Wealth Gini & 0.82 & 0.78 \\
\hline K/Y & 3.00 & 3.00 \\
Bequest/Wealth & $1-2 \%$ & $0.99 \%$ \\
\hline std of log earnings & 0.80 & 0.80 \\
Avg. Hours & 0.40 & 0.40 \\
\hline Interest rate (bond market) & & 2.00 \\
Mean return on wealth & 6.9 & 8.33 \\
Average return for $z_{1}$ & & 2.01 \\
Average return for $z 9$ & & 18.80 \\
Aggregate Debt/GDP & 0.68 & 1.27 \\
\% Constrained (all) & & 45.40 \\
\hline Mean Frisch Elasticity & & 1.22 \\
Median Frisch Elasticity & & 0.84 \\
\hline GDP share of total tax revenue & 0.295 & 25.01 \\
Revenue share of capital tax & 0.280 & 24.98 \\
GDP share of capital tax & 0.083 & 6.25 \\
Revenue share of labor tax & & 53.74 \\
GDP share of labor tax & & 13.44 \\
\hline Average labor tax rate & & 22.40 \\
\hline
\end{tabular}

\subsubsection{Distribution of Rate of Return}


TABle VIII - Percentiles of Rate of Return Distribution, Benchmark Model

\begin{tabular}{lccccccccc}
\hline & $\mathrm{p} 10$ & $\mathrm{p} 25$ & $\mathrm{p} 50$ & $\mathrm{p} 60$ & $\mathrm{p} 75$ & $\mathrm{p} 80$ & $\mathrm{p} 90$ & $\mathrm{p} 95$ & $\mathrm{p} 99.9$ \\
\hline Unweighted (\%) & 2 & 2 & 2 & 6.6 & 12 & 13.3 & 17.3 & 22.4 & 76.6 \\
(Wealth) weighted (\%) & 2 & 2 & 5.3 & 8.8 & 11.7 & 13.1 & 20.4 & 26.4 & 50.2 \\
\hline
\end{tabular}

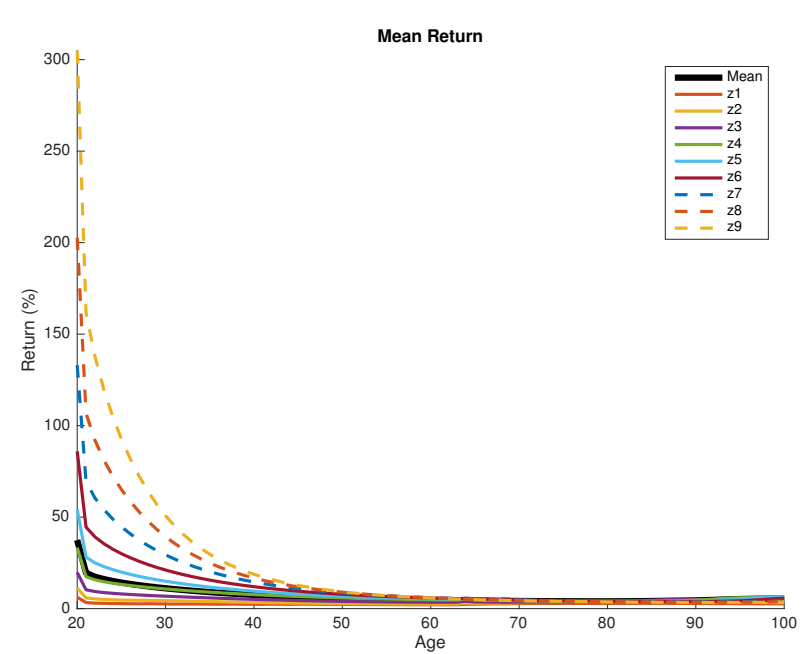

(A) Unweighted Returns

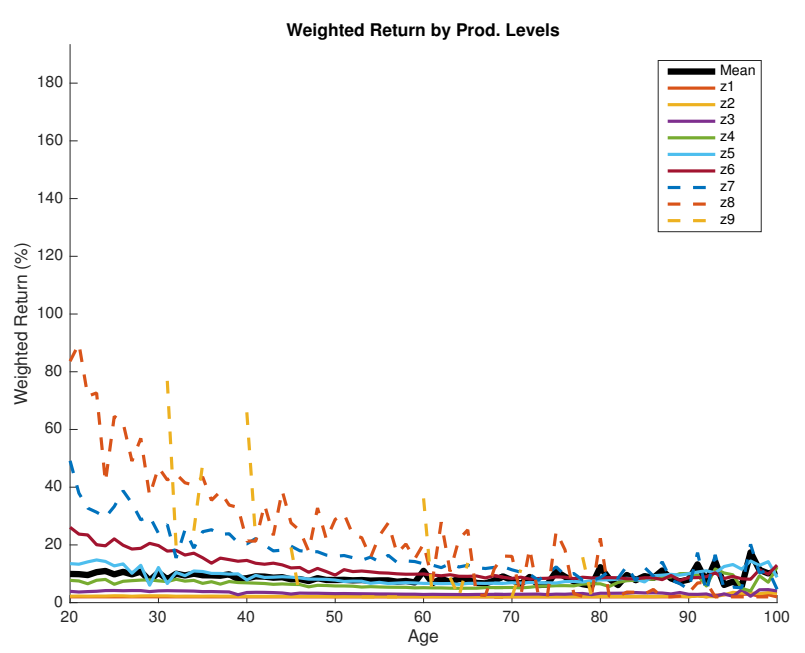

(B) Weighted Returns

Figure 1 - Deciles of the Rate of Return Distribution Over Life Cycle, Benchmark

\section{Standard Deviation of Return by Age}

Unweighted return - Assets The return for each age group is computed as:

$$
r=\frac{1}{T} \sum_{t} \frac{\operatorname{Pr}\left(a_{t}, z, x_{t}\right)+R a_{t}}{a_{t}}
$$

where:

$$
\operatorname{Pr}\left(a_{t}, z, x_{t}\right)=p\left(z_{t} k_{t}\right)^{\mu}-(R+\delta) k_{t} \quad k_{t}=\min \left\{\theta(z) a_{t}, k^{\star}\left(z, x_{t}\right)\right\}
$$

Weighted return - Assets The return for each age group is computed as:

$$
r=\frac{\sum_{t} \operatorname{Pr}\left(a_{t}, z, x_{t}\right)+R a_{t}}{\sum_{t} a_{t}}
$$


TABle IX - Unweighed Returns of Assets by Age Group - Benchmark Model

\begin{tabular}{l|lccccccccccc} 
Age & 20 & $21-25$ & $26-30$ & $31-35$ & $36-40$ & $41-45$ & $46-50$ & $51-55$ & $56-60$ & $61-65$ & $66-70$ & All \\
\hline Std Dev & 77.9 & 10.0 & 8.3 & 6.0 & 7.9 & 5.8 & 5.2 & 4.8 & 4.5 & 4.6 & 4.4 & 9.1 \\
Mean & 79.9 & 16.2 & 12.0 & 7.9 & 9.7 & 6.7 & 5.8 & 5.1 & 4.7 & 4.5 & 4.2 & 7.0 \\
\hline p99.9 & 690.6 & 71.5 & 58.6 & 40.1 & 45.3 & 33.0 & 30.0 & 28.4 & 25.7 & 25.9 & 22.4 & 76.6 \\
p99 & 416.6 & 47.2 & 38.4 & 27.5 & 35.1 & 24.5 & 21.1 & 19.0 & 17.8 & 19.8 & 18.9 & 42.7 \\
p95 & 219.0 & 31.9 & 25.9 & 18.0 & 23.7 & 17.2 & 15.5 & 14.4 & 13.9 & 14.4 & 14.1 & 22.3 \\
p90 & 148.3 & 28.9 & 22.9 & 15.4 & 19.8 & 14.5 & 13.3 & 12.5 & 12.1 & 12.1 & 11.9 & 17.3 \\
p75 & 96.6 & 20.0 & 16.1 & 11.4 & 15.3 & 11.3 & 10.0 & 8.6 & 6.7 & 5.0 & 2.0 & 12.0 \\
p50 & 63.7 & 15.3 & 11.5 & 7.2 & 8.0 & 3.5 & 2.0 & 2.0 & 2.0 & 2.0 & 2.0 & 2.0 \\
p25 & 32.8 & 9.5 & 5.3 & 1.6 & 2.4 & 2.0 & 2.0 & 2.0 & 2.0 & 2.0 & 2.0 & 2.0 \\
p10 & 16.9 & 5.3 & 2.0 & 1.6 & 2.4 & 2.0 & 2.0 & 2.0 & 2.0 & 2.0 & 2.0 & 2.0 \\
p1 & 5.8 & 2.0 & 2.0 & 1.6 & 2.4 & 2.0 & 2.0 & 2.0 & 2.0 & 2.0 & 2.0 & 2.0 \\
\hline
\end{tabular}

where:

$$
\operatorname{Pr}\left(a_{t}, z, x_{t}\right)=p\left(z_{t} k_{t}\right)^{\mu}-(R+\delta) k_{t} \quad k_{t}=\min \left\{\theta(z) a_{t}, k^{\star}\left(z, x_{t}\right)\right\}
$$

Table X - Weighed Returns of Assets by Age Group - Benchmark Model

\begin{tabular}{l|cccccccccccc} 
Age & 20 & $21-25$ & $26-30$ & $31-35$ & $36-40$ & $41-45$ & $46-50$ & $51-55$ & $56-60$ & $61-65$ & $66-70$ & All \\
\hline Std Dev & 8.1 & 9.6 & 8.2 & 7.4 & 6.5 & 5.8 & 5.2 & 4.8 & 4.5 & 4.4 & 4.4 & 8.5 \\
Mean & 7.4 & 15.5 & 11.9 & 9.8 & 8.0 & 6.7 & 5.8 & 5.1 & 4.6 & 4.4 & 4.2 & 8.4 \\
\hline p99.9 & 76.6 & 68.1 & 57.5 & 49.2 & 38.6 & 32.5 & 29.6 & 28.1 & 25.8 & 23.5 & 22.3 & 27.9 \\
p99 & 39.3 & 45.5 & 38.1 & 34.2 & 28.8 & 23.9 & 20.7 & 18.8 & 17.7 & 18.1 & 18.8 & 26.6 \\
p95 & 19.2 & 30.7 & 25.7 & 22.4 & 19.5 & 17.1 & 15.4 & 14.3 & 13.8 & 14.1 & 14.1 & 22.0 \\
p90 & 15.2 & 27.8 & 22.6 & 19.1 & 16.3 & 14.4 & 13.3 & 12.5 & 12.0 & 12.0 & 11.9 & 17.0 \\
p75 & 10.1 & 19.3 & 16.0 & 14.1 & 12.7 & 11.2 & 10.0 & 8.6 & 6.7 & 5.0 & 2.0 & 11.1 \\
p50 & 4.6 & 14.4 & 11.3 & 8.9 & 6.6 & 3.4 & 2.0 & 2.0 & 2.0 & 2.0 & 2.0 & 4.6 \\
p25 & 2.2 & 9.0 & 5.2 & 2.0 & 2.0 & 2.0 & 2.0 & 2.0 & 2.0 & 2.0 & 2.0 & 2.0 \\
p10 & 2.0 & 4.8 & 2.0 & 2.0 & 2.0 & 2.0 & 2.0 & 2.0 & 2.0 & 2.0 & 2.0 & 2.0 \\
p1 & 2.0 & 2.0 & 2.0 & 2.0 & 2.0 & 2.0 & 2.0 & 2.0 & 2.0 & 2.0 & 2.0 & 2.0 \\
\hline
\end{tabular}

Unweighted return - Capital The return for each age group is computed as:

$$
r=\frac{1}{\sum_{t} 1_{\left\{k_{t}>0\right\}}} \sum_{t} \frac{\operatorname{Pr}\left(a_{t}, z, x_{t}\right)+R a_{t}}{k_{t}} 1_{\left\{k_{t}>0\right\}}
$$

where:

$$
\operatorname{Pr}\left(a_{t}, z, x_{t}\right)=p\left(z_{t} k_{t}\right)^{\mu}-(R+\delta) k_{t} \quad k_{t}=\min \left\{\theta(z) a_{t}, k^{\star}\left(z, x_{t}\right)\right\}
$$


TABle XI - Unweighed Returns of Capital by Age Group - Benchmark Model

\begin{tabular}{l|cccccccccccc} 
Age & 20 & $21-25$ & $26-30$ & $31-35$ & $36-40$ & $41-45$ & $46-50$ & $51-55$ & $56-60$ & $61-65$ & $66-70$ & All \\
\hline Std Dev & 8.1 & 9.6 & 8.2 & 7.4 & 6.5 & 5.8 & 5.2 & 4.8 & 4.5 & 4.4 & 4.4 & 8.5 \\
Mean & 7.4 & 15.5 & 11.9 & 9.8 & 8.0 & 6.7 & 5.8 & 5.1 & 4.6 & 4.4 & 4.2 & 8.4 \\
\hline p99.9 & 76.6 & 68.1 & 57.5 & 49.2 & 38.6 & 32.5 & 29.6 & 28.1 & 25.8 & 23.5 & 22.3 & 27.9 \\
p99 & 39.3 & 45.5 & 38.1 & 34.2 & 28.8 & 23.9 & 20.7 & 18.8 & 17.7 & 18.1 & 18.8 & 26.6 \\
p95 & 19.2 & 30.7 & 25.7 & 22.4 & 19.5 & 17.1 & 15.4 & 14.3 & 13.8 & 14.1 & 14.1 & 22.0 \\
p90 & 15.2 & 27.8 & 22.6 & 19.1 & 16.3 & 14.4 & 13.3 & 12.5 & 12.0 & 12.0 & 11.9 & 17.0 \\
p75 & 10.1 & 19.3 & 16.0 & 14.1 & 12.7 & 11.2 & 10.0 & 8.6 & 6.7 & 5.0 & 2.0 & 11.1 \\
p50 & 4.6 & 14.4 & 11.3 & 8.9 & 6.6 & 3.4 & 2.0 & 2.0 & 2.0 & 2.0 & 2.0 & 4.6 \\
p25 & 2.2 & 9.0 & 5.2 & 2.0 & 2.0 & 2.0 & 2.0 & 2.0 & 2.0 & 2.0 & 2.0 & 2.0 \\
p10 & 2.0 & 4.8 & 2.0 & 2.0 & 2.0 & 2.0 & 2.0 & 2.0 & 2.0 & 2.0 & 2.0 & 2.0 \\
p1 & 2.0 & 2.0 & 2.0 & 2.0 & 2.0 & 2.0 & 2.0 & 2.0 & 2.0 & 2.0 & 2.0 & 2.0 \\
\hline
\end{tabular}

Weighted return - Capital The return for each age group is computed as:

$$
r=\frac{\sum_{t} \operatorname{Pr}\left(a_{t}, z, x_{t}\right)+R a_{t} 1_{\left\{k_{t}>0\right\}}}{\sum_{t} k_{t}}
$$

where:

$$
\operatorname{Pr}\left(a_{t}, z, x_{t}\right)=p\left(z_{t} k_{t}\right)^{\mu}-(R+\delta) k_{t} \quad k_{t}=\min \left\{\theta(z) a_{t}, k^{\star}\left(z, x_{t}\right)\right\}
$$

TABle XII - Weighed Returns of Capital by Age Group - Benchmark Model

\begin{tabular}{l|lccccccccccc} 
Age & 20 & $21-25$ & $26-30$ & $31-35$ & $36-40$ & $41-45$ & $46-50$ & $51-55$ & $56-60$ & $61-65$ & $66-70$ & All \\
\hline Std Dev & 46.4 & 32.9 & 30.6 & 29.4 & 28.5 & 27.9 & 27.5 & 27.3 & 27.1 & 27.3 & 27.7 & 12.7 \\
Mean & 21.5 & 10.8 & 9.3 & 8.6 & 8.1 & 7.8 & 7.6 & 7.4 & 7.4 & 7.5 & 7.7 & 7.7 \\
\hline p99.9 & 87.3 & 73.8 & 65.7 & 87.4 & 128.7 & 177.0 & 190.9 & 234.9 & 193.6 & 183.9 & 119.4 & 17.7 \\
p99 & 62.1 & 24.3 & 20.8 & 19.1 & 17.5 & 16.7 & 16.3 & 15.8 & 15.1 & 13.6 & 12.8 & 16.5 \\
p95 & 43.8 & 18.8 & 15.5 & 14.0 & 12.8 & 11.8 & 11.0 & 10.5 & 10.2 & 10.8 & 11.5 & 14.3 \\
p90 & 43.8 & 16.1 & 13.8 & 12.5 & 11.3 & 10.4 & 9.7 & 9.3 & 9.1 & 9.7 & 10.2 & 12.6 \\
p75 & 30.5 & 12.6 & 10.7 & 9.8 & 9.1 & 8.5 & 8.1 & 7.9 & 7.8 & 8.1 & 8.6 & 9.7 \\
p50 & 16.9 & 10.3 & 9.0 & 8.2 & 7.6 & 7.2 & 6.9 & 6.7 & 6.7 & 6.8 & 7.2 & 6.6 \\
p25 & 8.3 & 7.5 & 6.6 & 6.2 & 5.9 & 5.6 & 5.4 & 5.3 & 5.3 & 5.6 & 6.0 & 5.1 \\
p10 & 6.0 & 5.1 & 4.7 & 4.4 & 4.2 & 4.0 & 3.9 & 3.8 & 3.9 & 4.0 & 4.5 & 3.3 \\
p1 & 3.1 & 2.9 & 2.9 & 2.9 & 2.9 & 2.7 & 2.7 & 2.6 & 2.7 & 2.7 & 2.8 & 2.1 \\
\hline
\end{tabular}


TABle XIII - Percentiles of Wealth Distribution

\begin{tabular}{c|ccccccccc}
\hline & $\mathrm{p} 10$ & $\mathrm{p} 25$ & $\mathrm{p} 50$ & $\mathrm{p} 60$ & $\mathrm{p} 75$ & $\mathrm{p} 80$ & $\mathrm{p} 90$ & $\mathrm{p} 95$ & $\mathrm{p} 99.9$ \\
\hline Assets & 7.5 & 10713.5 & 66432.6 & 109603.9 & 221621.9 & 282558.9 & 503725.9 & 788464.5 & 12127732.9 \\
\hline
\end{tabular}

\subsubsection{Wealth distribution, the Pareto tail, and assets deciles.}

Figure 2 - Asset Deciles by Age

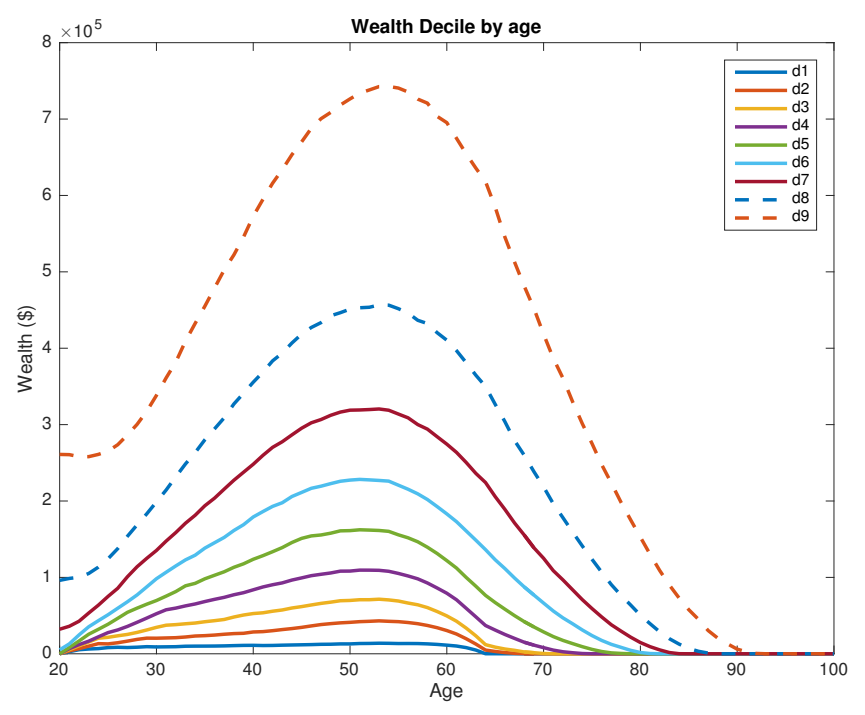

There are two formats we have used for the Pareto tail graph I'm attaching them both.

TABLE XIV - Pareto Coefficient for distribution of wealth above 1 million dollars

\begin{tabular}{|l|c|}
\hline & Baseline \\
\hline \hline Tail Coeff. $W>1 e 6$ & 1.46 \\
\hline
\end{tabular}


Figure 3 - Pareto Tail - Wealth above 1.000.000

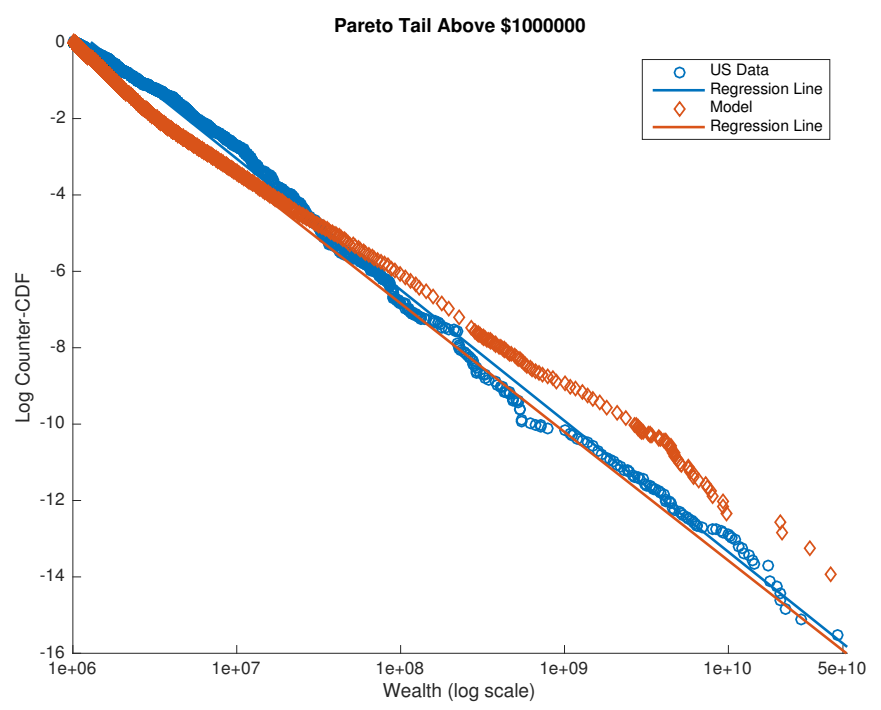

\subsubsection{Intergenerational mobility and self-made entrepreneurs}

FIGURE 4 - Intergenerational wealth relation

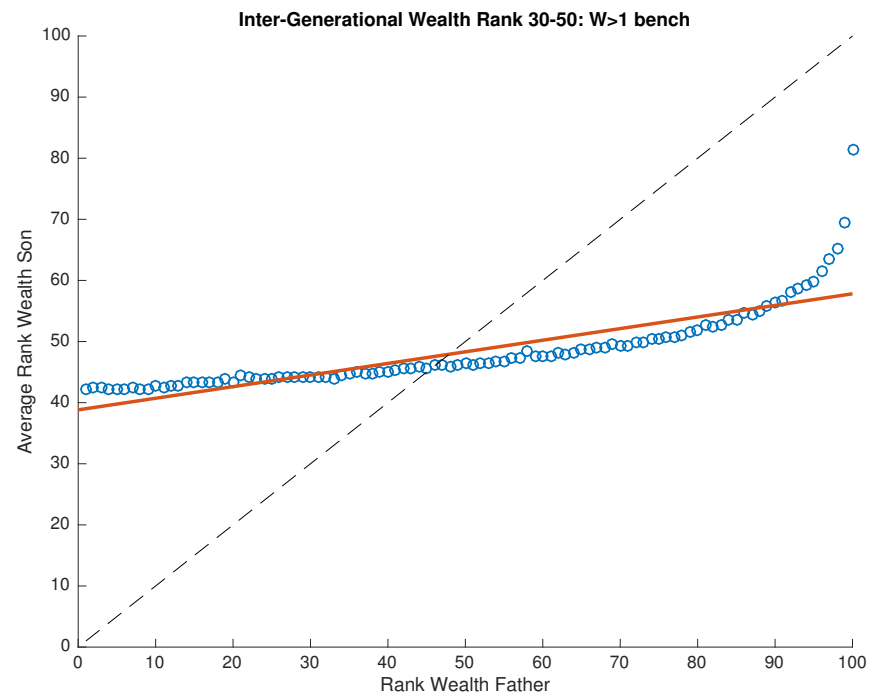

The figure plots the average rank of the son's wealth for each percentile of father's wealth. The wealth is computed as average wealth for an agent between the ages of 30 and 50. The coefficient of the regression is 0.19.

\begin{tabular}{|c|c|c|c}
\hline Wealth & Pistaferri & Kopczuk & Baseline \\
\hline \hline Coeff. & 0.29 & 0.24 & 0.190 \\
\hline
\end{tabular}


FigURE 5 - Intergenerational return relation

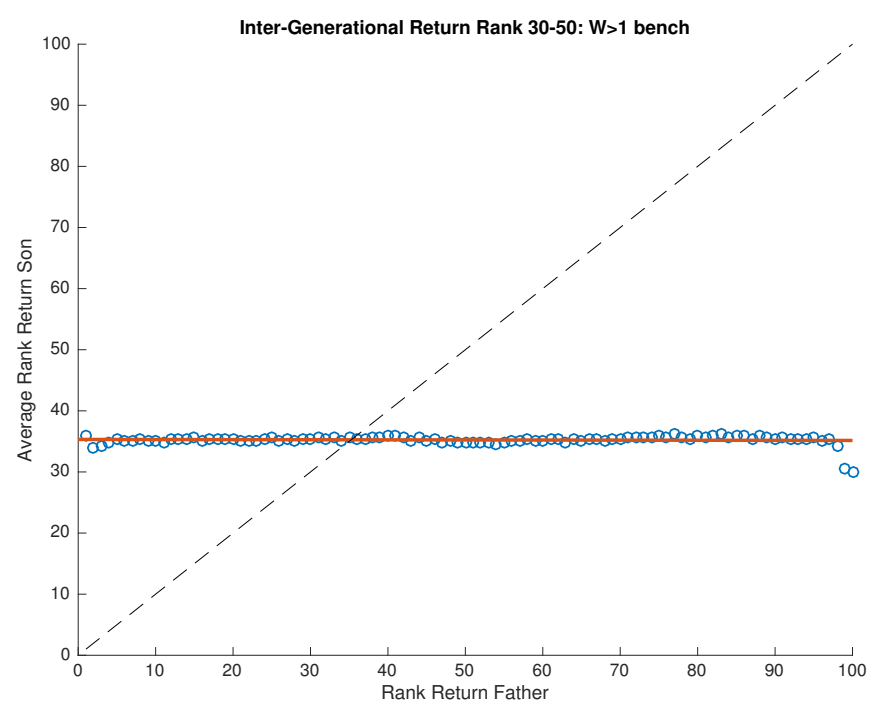

The figure plots the average rank of the son's return for each percentile of father's return. The return is computed as average return for an agent between the ages of 30 and 50. The coefficient of the regression is -0.002 .

\begin{tabular}{|c|c|c}
\hline & Pistaferri & Book Value \\
\hline \hline Coeff. & & -0.002 \\
\hline
\end{tabular}

\subsubsection{Top 80 Agents}

TABlE XV - Statistics on the Top 80 agents of the simulation

\begin{tabular}{lc}
\hline$W_{N B}<1,000,000$ & $38.8 \%$ \\
Initial percentile $<90$ & $38.8 \%$ \\
$W_{N B} / W_{T}>100$ & $50.0 \%$ \\
$W_{N B} / W_{T}>1,000$ & $47.5 \%$ \\
Constrained Initial & $55.0 \%$ \\
Constrained Final & $27.5 \%$ \\
Mean Leverage Initial & $32.1 \%$ \\
Mean Leverage Final & $-26.4 \%$ \\
\hline
\end{tabular}

Leverage is measured as the debt-to-equity ratio. 
TABLE XVI - Forbes Self-made Index, APPENDIX

\begin{tabular}{clc}
\hline & Description & Fraction 2015 \\
\hline \hline 1 & Inherited fortune but not working to increase it & 7.00 \\
2 & Inherited fortune and has a role managing it & 4.75 \\
3 & Inherited fortune and helping to increase it marginally & 5.50 \\
4 & Inherited fortune and increasing it in a meaningful way & 5.25 \\
5 & Inherited small or medium-size business and made it into a ten-digit fortune & 8.50 \\
6 & Hired or hands-off investor who didn't create the business & 2.25 \\
7 & Self-made who got a head start from wealthy parents and moneyed background & 10.00 \\
8 & Self-made who came from a middle- or upper-middle-class background & 32.00 \\
9 & Self-made who came from a largely working-class background; rose from little to nothing & 14.50 \\
10 & Self-made who not only grew up poor but also overcame significant obstacles & 7.75 \\
\hline & Self-made 7-10 & 64.25 \\
\hline
\end{tabular}

Figure 6 - Age histogram of top 80 agents

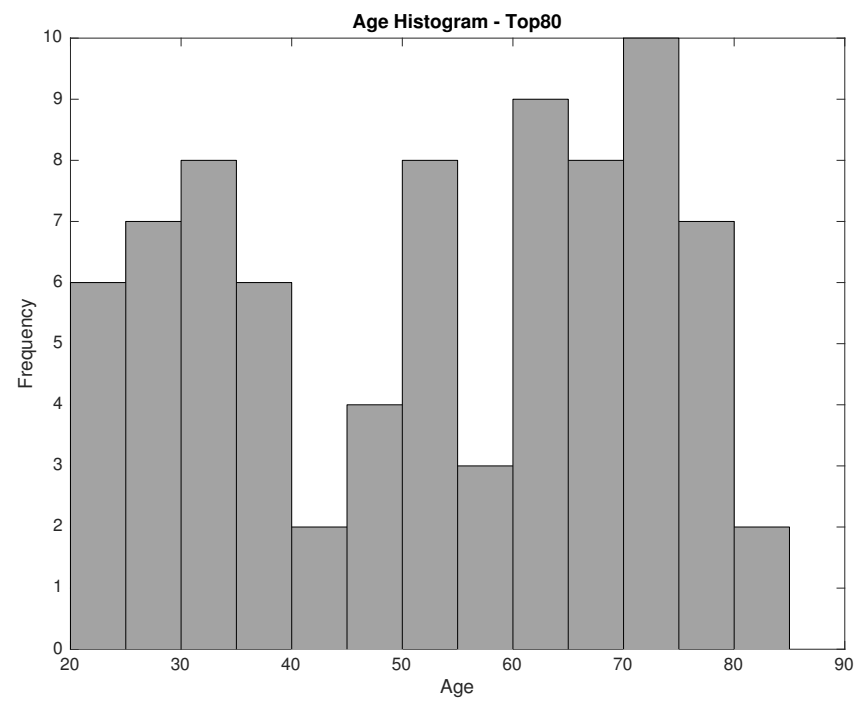


FiguRE 7 - Average Income Composition of top 80 agents

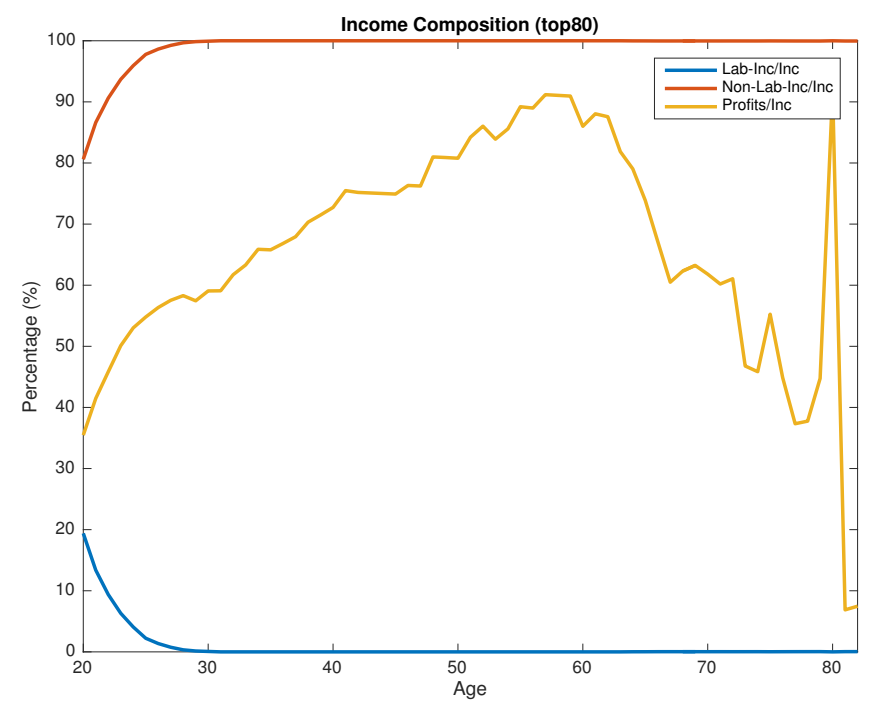

This is obtained by computing the average of the share of each source of income on total income for the top 80 in each age. As the age increases the sample size decreases.

FiguRE 8 - Average Return of top 80 agents

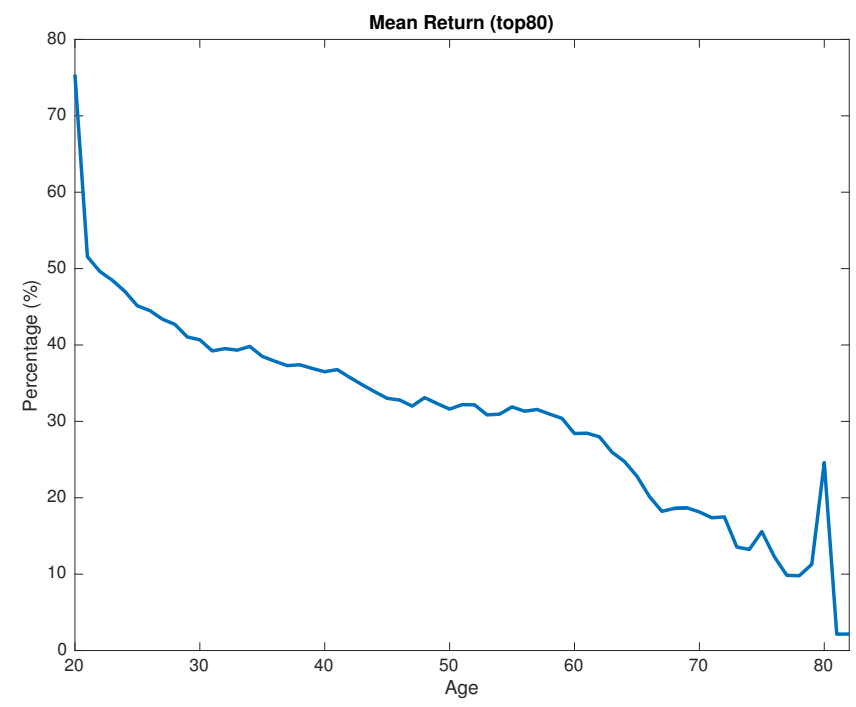

This is obtained by computing the average of the return (non-labor income)/assets for the top 80 in each age. As the age increases the sample size decreases. 


\subsubsection{Constrained producers and leverage.}

TABLE XVII - Optimal capital level and percentage of constrained agents by productivity

\begin{tabular}{|r|r|r|r|r|}
\hline & \multicolumn{4}{|c|}{ Book Value } \\
\hline & \multicolumn{2}{|c|}{ High Shock } & \multicolumn{2}{|c|}{ Low Shock } \\
\hline & $\mathrm{K}$ & Const. & $\mathrm{K}$ & Const. \\
\hline \hline$z_{1}$ & & & 3990 & 32.6 \\
\hline$z_{2}$ & & & 116742 & 70.2 \\
\hline$z_{3}$ & & & 3029913 & 99.5 \\
\hline$z_{4}$ & & & 78638108 & 100.0 \\
\hline$z_{5}$ & 2040966891 & 100.0 & 150825105 & 100.0 \\
\hline$z_{6}$ & 52971084173 & 100.0 & 289277209 & 100.0 \\
\hline$z_{7}$ & 1374807093290 & 100.0 & 554823437 & 99.9 \\
\hline$z_{8}$ & 35681628444367 & 100.0 & 1064131696 & 97.5 \\
\hline$z_{9}$ & 926078003710803 & 100.0 & 2040966891 & 91.3 \\
\hline
\end{tabular}

Figure 9 - Constrained Firms by productivity and age

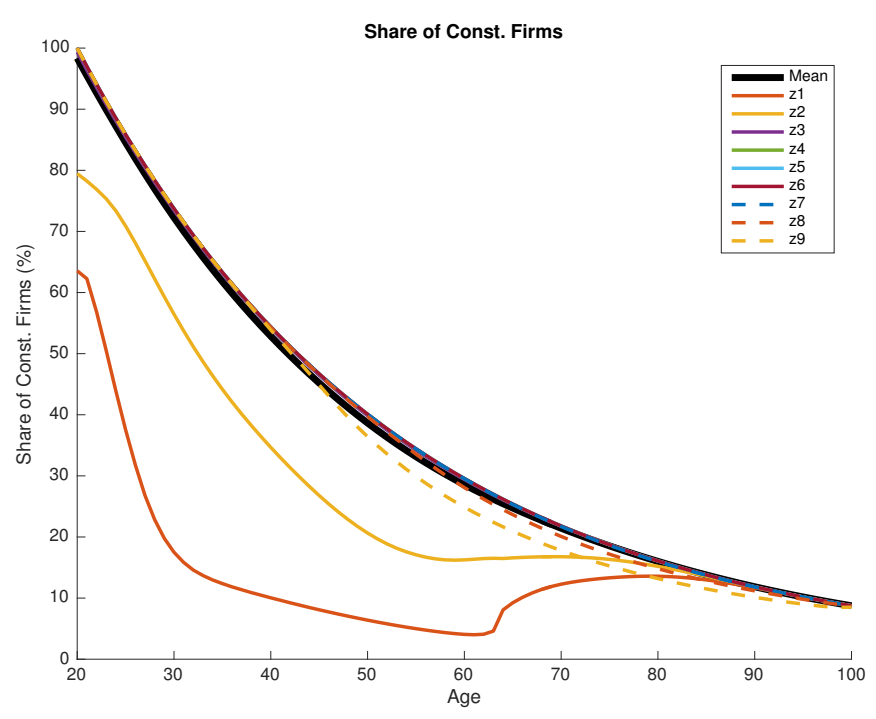


FIgURE 10 - Constrained Firms by wealth decile and age

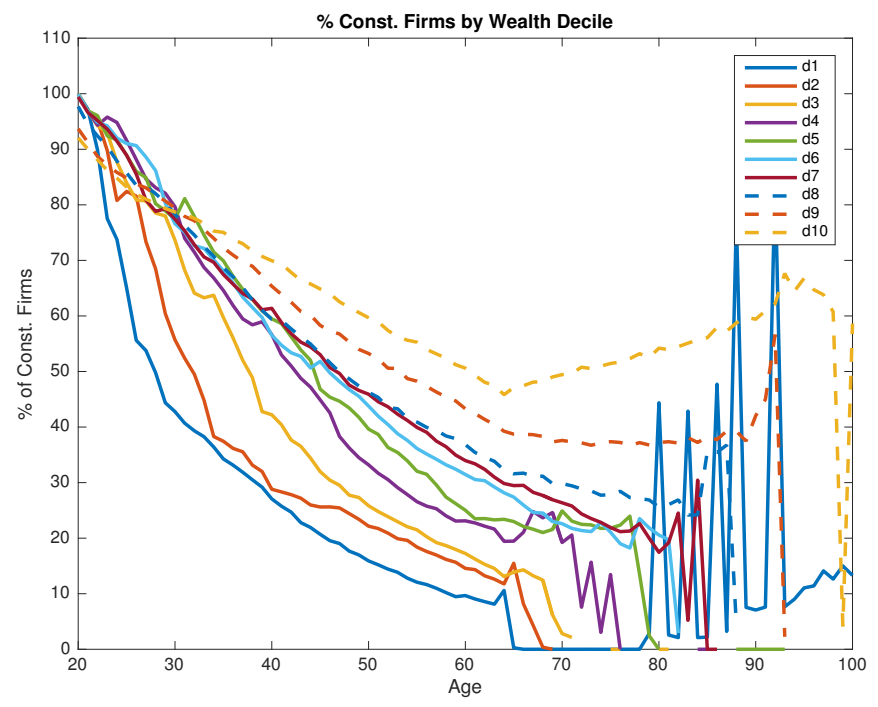

\subsubsection{Leverage (Leverage is measured as the debt-to-equity ratio. )}

TABLE XVIII - Percentiles of leverage distribution

\begin{tabular}{|c|c|c|c|c|c|c|c|c|c|}
\hline & $\mathrm{p} 10$ & $\mathrm{p} 25$ & $\mathrm{p} 50$ & $\mathrm{p} 60$ & $\mathrm{p} 75$ & $\mathrm{p} 80$ & $\mathrm{p} 90$ & $\mathrm{p} 95$ & $\mathrm{p} 99.9$ \\
\hline Leverage & 0 & 0 & 0 & 37.5 & 56.3 & 56.3 & 75 & 75 & 112.5 \\
\hline
\end{tabular}

Leverage is measured as the debt-to-equity ratio. 
Figure 11 - Leverage by productivity and age

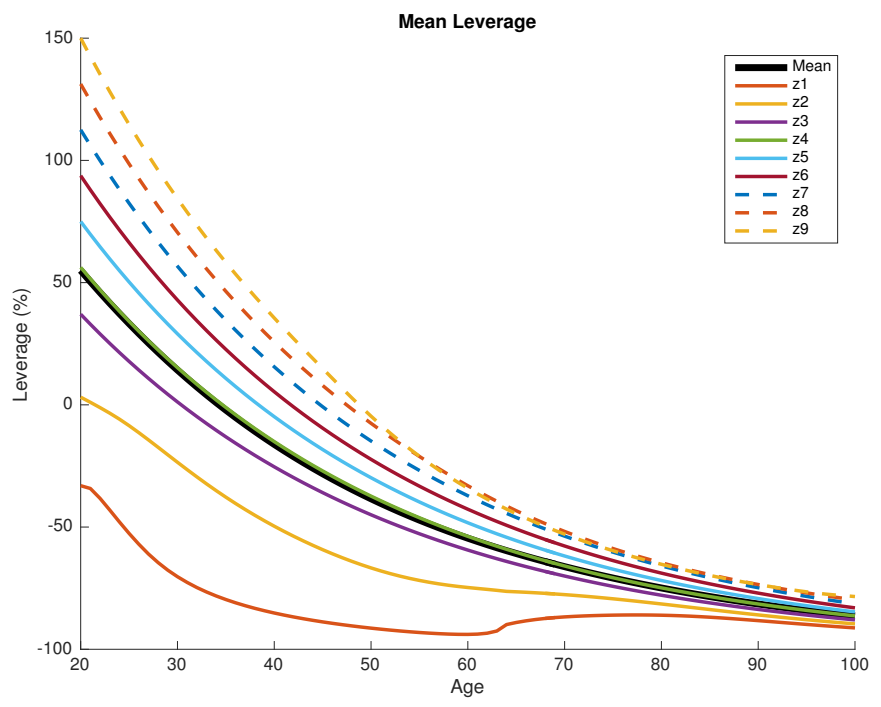

Leverage is measured as the debt-to-equity ratio.

Figure 12 - Percentage of Borrowers and Lenders by Age

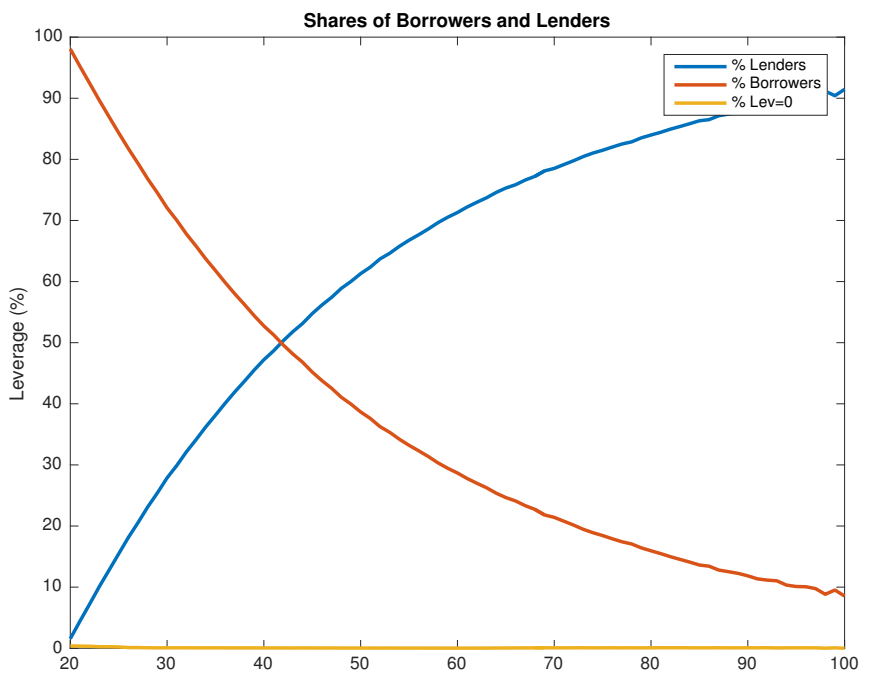

Leverage is measured as the debt-to-equity ratio.

\subsubsection{Entrepreneurship}

TABLE XIX - Share of the population by profits over other income

\begin{tabular}{c|cccccccccc}
\hline$P r / Y-P r$ & $0-10$ & $10-20$ & $20-30$ & $30-40$ & $40-50$ & $50-60$ & $60-70$ & $70-80$ & $90-100$ & $>100$ \\
\hline \% of population & 62.64 & 8.68 & 5.84 & 4.15 & 2.9 & 2.13 & 1.65 & 1.27 & 1.03 & 8.89 \\
\hline
\end{tabular}




\section{$5 \quad$ Results}

\subsection{Tax Reform}

We implement a revenue-neutral tax reform that replaces the capital income tax with a wealth tax and analyze the aggregate and distributional outcomes across steady states. In the policy experiment the proportional labor income tax $\tau_{l}$ remains unchanged, but the capital income tax $\tau_{k}$ is set to zero. In order to balance the government's budget, we find a wealth tax rate $\tau_{a}$ such that the government raises the same amount of tax revenue as in the benchmark economy. We find that in order to achieve this, the wealth tax rate $\tau_{a}$ should be $1.13 \%$.

TABLE XX - Statistics of Benchmark model vs Tax Reform

\begin{tabular}{lc|r|rrr} 
& \multirow{2}{*}{ Data } & Benchmark & \multicolumn{3}{|c}{ Tax Reform } \\
\cline { 4 - 6 } & & & \multicolumn{1}{|c}{$\tau_{a}$} & $\tau_{a}+\mathrm{SS}$ & $\tau_{c}$ \\
\hline Top 1\% & 0.357 & 0.36 & 0.46 & 0.48 & 0.42 \\
Top 10\% & 0.75 & 0.66 & 0.72 & 0.74 & 0.70 \\
Top 20\% & & 0.81 & 0.84 & 0.85 & 0.83 \\
Wealth Gini & 0.82 & 0.78 & 0.82 & 0.83 & 0.81 \\
\hline K/Y & 3.00 & 3.00 & 3.25 & 3.12 & 3.56 \\
BQ/Wealth & $1-2$ & 0.99 & 1.07 & 1.06 & 1.06 \\
\hline std-earnings & 0.80 & 0.80 & 0.80 & 0.79 & 0.80 \\
Avg. Hours & 0.40 & 0.40 & 0.41 & 0.41 & 0.40 \\
\hline r & & 2.00 & 1.74 & 2.05 & 1.06 \\
Mean Return & & 8.33 & 7.29 & 7.80 & 6.23 \\
Return z_\{1\} & & 2.01 & 1.74 & 2.05 & 1.06 \\
Return z_\{9\} & & 18.80 & 15.49 & 15.98 & 14.32 \\
Debt/Output & & 1.27 & 1.41 & 1.36 & 1.53 \\
\% Constrained (all) & & 45.40 & 44.98 & 45.10 & 45.28 \\
\hline Av Frisch El. & & 1.22 & 1.17 & 1.12 & 1.27 \\
Frisch El. (Av) & & 0.84 & 0.83 & 0.82 & 0.84 \\
\hline Tax_Rev/GDP & 29.5 & 25.01 & 22.72 & 23.98 & 21.93 \\
KW_Rev/Rev & 28.0 & 24.98 & 17.42 & 21.66 & 0.00 \\
KW_Rev/GDP & 8.26 & 6.25 & 3.96 & 5.20 & 0.00 \\
L_Rev/Rev & & 53.74 & 59.17 & 56.04 & 61.29 \\
L_Rev/GDP & & 13.44 & 13.44 & 13.44 & 13.44 \\
\hline Average L Tax & & 22.40 & 22.40 & 22.40 & 22.40 \\
\hline
\end{tabular}


Saving rates. Figure 13 illustrates the changes in saving rates by wealth for agents with the lowest, median, and highest entrepreneurial shocks $z$ at ages 20 and 36 when the capital income tax is replaced with a wealth tax. Consistent with our prediction, we observe that the savings rates of the agents with the highest ability increase when we switch from a capital income tax to a wealth tax. For the agents with the lowest and median abilities the savings rates decrease. Similar patterns arise for other ages too. Due to the observed changes in savings rates, the higher ability individuals accumulate even more wealth under the wealth tax, and as a result own a higher share of total wealth.

Figure 13 - Change in Savings Rates

(A) Age 20

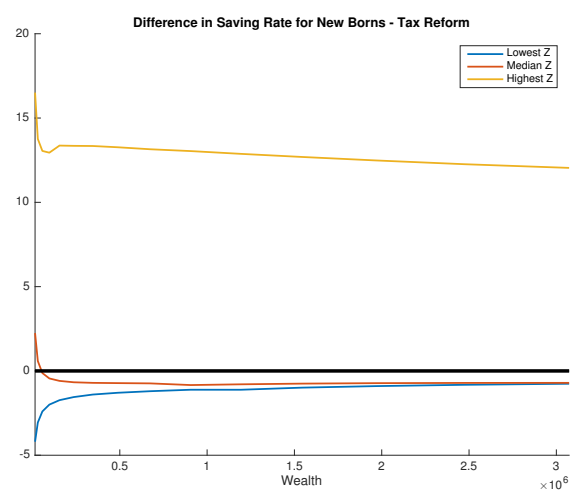

(B) Age 36

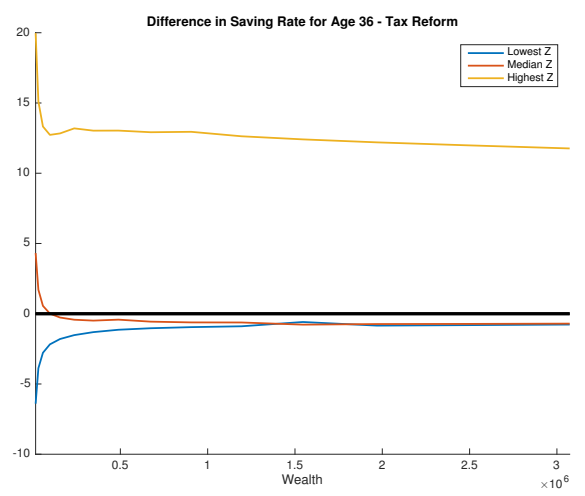

TABLE XXI - Wealth Statistics

\begin{tabular}{lccccc}
\hline & \multirow{2}{*}{ Data } & \multirow{2}{*}{ Benchmark } & \multicolumn{4}{c}{ Tax Reform } \\
\cline { 3 - 6 } & & & $\tau_{a}$ & $\tau_{a}+\mathrm{SS}$ & $\tau_{c}$ \\
\hline \hline Top 1\% & 0.357 & 0.357 & 0.46 & 0.46 & 0.48 \\
Top 10\% & 0.75 & 0.66 & 0.72 & 0.72 & 0.74 \\
Wealth/Output & 3.00 & 3.00 & 3.25 & 3.12 & 3.56 \\
Average hours & 0.40 & 0.40 & 0.41 & 0.41 & 0.40 \\
Std of log earnings & 0.80 & 0.80 & 0.80 & 0.79 & 0.80 \\
Bequest/Wealth & $1-2 \%$ & 0.99 & 1.07 & 1.06 & 1.06 \\
\hline
\end{tabular}

Wealth Distribution. Table XXI shows the key wealth statistics in the benchmark and the counterfactual economy. Consistent with the changes in savings rates, we observe that the wealth distribution becomes more concentrated at the top when we move from 
an economy with a capital income tax to a one with a wealth tax. The fraction of wealth held by the households in the top 1 percent increases from 36 percent to 46 percent, while the fraction of wealth held by the households in the top 10 percent increases from 66 percent to 72 percent. The wealth-to-output ratio also increases from 3 to 3.25 .

Aggregate Variables. Table XXII lists the aggregate variables in the two economies. Since wealth is more concentrated in the hands of more productive agents under wealth tax, the aggregate intermediate goods aggregator increases by 24.8 percent. Therefore, the aggregate output increases by 10.1 percent.

TABLE XXII - Equilibrium Variables

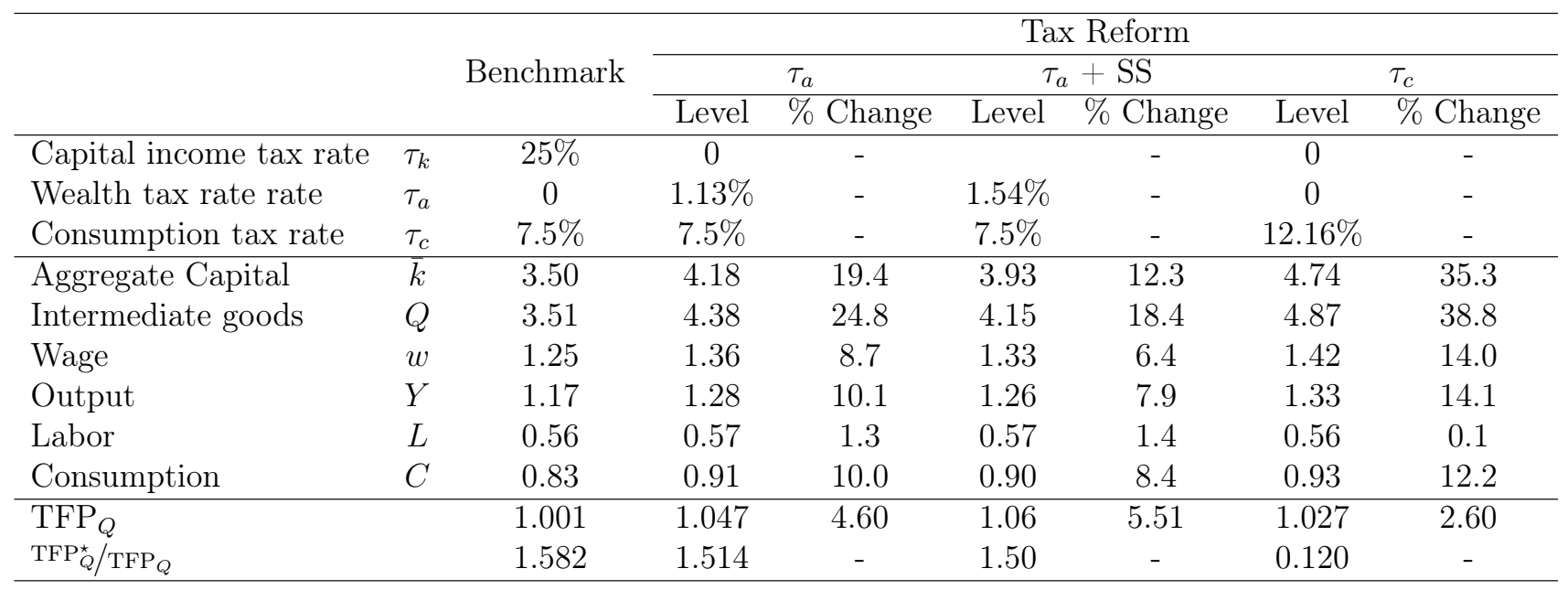

Welfare. Given our utility function specification, the welfare consequences of switching from the benchmark economy to a counterfactual economy with a wealth tax for a household in state $\mathbf{S}$ with age $h$ and wealth $a$ is given by

$$
C E_{h}(a, \mathbf{S})=100 \times\left[\left(\frac{V_{h}\left(a, \mathbf{S} ; \tau^{\text {policy }}\right)}{V_{h}\left(a, \mathbf{S} ; \tau^{\text {bench }}\right)}\right)^{1 / \gamma(1-\sigma)}-1\right] .
$$

This measure specifically gives what fraction of consumption a household is willing to pay in order to move from the steady state of the economy with a capital income tax to the steady state of the economy with a wealth tax. 
TABle XXIII - Welfare Gain by Age Group and Entrepreneurial Ability

(A) Tax Reform $\left(\tau_{a}\right)$

\begin{tabular}{cccccccccc}
\hline \hline & \multicolumn{10}{c}{ Productivity group } \\
\cline { 2 - 10 } Age & $z_{1}$ & $z_{2}$ & $z_{3}$ & $z_{4}$ & $z_{5}$ & $z_{6}$ & \multicolumn{1}{c}{$z_{7}$} & \multicolumn{1}{c}{$z_{8}$} & \multicolumn{1}{c}{$z_{9}$} \\
\cline { 2 - 10 } $20-25$ & $\mathbf{7 . 3}$ & $\mathbf{7 . 2}$ & $\mathbf{6 . 8}$ & $\mathbf{6 . 8}$ & $\mathbf{7 . 4}$ & $\mathbf{8 . 8}$ & $\mathbf{1 0 . 5}$ & $\mathbf{1 1 . 1}$ & $\mathbf{1 0 . 7}$ \\
$25-34$ & 7.0 & 6.9 & 6.4 & 6.0 & 5.9 & 6.0 & 5.9 & 3.7 & 1.2 \\
$35-44$ & 6.1 & 6.0 & 5.4 & 4.9 & 4.3 & 3.3 & 1.4 & -1.7 & -4.3 \\
$45-54$ & 4.6 & 4.5 & 4.1 & 3.5 & 2.8 & 1.7 & -0.5 & -3.1 & -5.2 \\
$55-64$ & 1.9 & 1.9 & 1.6 & 1.3 & 0.9 & 0.0 & -1.6 & -3.5 & -5.3 \\
$65-74$ & -0.3 & -0.3 & -0.4 & -0.5 & -0.6 & -1.0 & -2.1 & -3.4 & -4.7 \\
$75+$ & -0.1 & -0.1 & -0.1 & -0.1 & -0.1 & -0.4 & -1.0 & -1.9 & -2.7 \\
\hline
\end{tabular}

(B) Tax Reform $\left(\tau_{a}\right)+\mathrm{SS}$

\begin{tabular}{cccccccccc}
\multicolumn{10}{c}{ Baseline + SS reform } \\
\hline \hline \multirow{2}{*}{ Age } & \multicolumn{10}{c}{ Productivity group } \\
\cline { 2 - 10 } $20-25$ & $z_{1}$ & $z_{2}$ & $z_{3}$ & $z_{4}$ & $z_{5}$ & $z_{6}$ & $z_{7}$ & \multicolumn{1}{c}{$z_{8}$} & \multicolumn{1}{c}{$z_{9}$} \\
\cline { 2 - 10 } $25-34$ & 5.3 & 5.2 & 4.8 & $\mathbf{4 . 9}$ & $\mathbf{5 . 7}$ & $\mathbf{7 . 4}$ & $\mathbf{9 . 6}$ & $\mathbf{1 0 . 6}$ & $\mathbf{1 0 . 4}$ \\
$35-44$ & 4.9 & 4.8 & 4.3 & 4.4 & 4.5 & 5.0 & 5.2 & 3.2 & 0.6 \\
$45-54$ & 4.8 & 4.7 & 4.3 & 3.8 & 3.4 & 2.8 & 0.9 & -2.4 & -5.3 \\
$55-64$ & 5.6 & 5.6 & 5.3 & 4.8 & 4.3 & 3.1 & 0.8 & -1.9 & -4.3 \\
$65-74$ & 7.0 & 7.0 & 6.8 & 6.3 & 5.8 & 4.7 & 2.6 & 0.1 & -2.2 \\
$75+$ & 7.7 & 7.7 & 7.6 & 7.4 & 7.0 & 6.2 & 4.5 & 2.5 & 0.6 \\
\hline
\end{tabular}

(C) Tax Reform $\left(\tau_{c}\right)$

Baseline + TauC

\begin{tabular}{cccccccccc}
\hline \hline & \multicolumn{10}{c}{ Productivity group } \\
\cline { 2 - 10 } Age & $z_{1}$ & $z_{2}$ & $z_{3}$ & $z_{4}$ & $z_{5}$ & $z_{6}$ & $z_{7}$ & $z_{8}$ & $z_{9}$ \\
\cline { 2 - 10 } $20-25$ & $\mathbf{7 . 8 6}$ & $\mathbf{7 . 7 5}$ & $\mathbf{7 . 5 6}$ & $\mathbf{7 . 5 6}$ & $\mathbf{7 . 8 2}$ & $\mathbf{8 . 5 4}$ & $\mathbf{9 . 4 0}$ & $\mathbf{9 . 4 5}$ & $\mathbf{8 . 7 9}$ \\
$25-34$ & 7.53 & 7.41 & 7.07 & 6.66 & 6.25 & 5.91 & 5.34 & 3.53 & 1.71 \\
$35-44$ & 6.33 & 6.22 & 5.82 & 5.18 & 4.41 & 3.37 & 1.69 & -0.50 & -2.28 \\
$45-54$ & 4.09 & 4.01 & 3.65 & 3.03 & 2.31 & 1.23 & -0.44 & -2.27 & -3.82 \\
$55-64$ & -0.41 & -0.46 & -0.65 & -0.93 & -1.24 & -1.81 & -2.81 & -4.02 & -5.14 \\
$65-74$ & -4.30 & -4.31 & -4.31 & -4.22 & -4.15 & -4.23 & -4.62 & -5.22 & -5.87 \\
$75+$ & -4.18 & -4.18 & -4.18 & -4.15 & -4.11 & -4.13 & -4.35 & -4.72 & -5.12 \\
\hline
\end{tabular}


TABLE XXIV - Fraction with Positive Welfare Gain by Age Group and Entrepreneurial Ability

(A) Tax Reform $\left(\tau_{a}\right)$

\begin{tabular}{cccccccccc}
\hline \hline & \multicolumn{10}{c}{ Productivity group } \\
\cline { 2 - 10 } Age & $z_{1}$ & $z_{2}$ & $z_{3}$ & $z_{4}$ & $z_{5}$ & $z_{6}$ & $z_{7}$ & $z_{8}$ & $z_{9}$ \\
\cline { 2 - 10 } $20-25$ & 0.98 & 0.98 & 0.96 & 0.96 & 0.97 & 0.97 & 0.97 & 0.97 & 0.94 \\
$25-34$ & 0.99 & 0.99 & 0.98 & 0.97 & 0.95 & 0.94 & 0.89 & 0.78 & 0.59 \\
$35-44$ & 0.98 & 0.98 & 0.97 & 0.95 & 0.91 & 0.84 & 0.67 & 0.45 & 0.34 \\
$45-54$ & 0.96 & 0.96 & 0.93 & 0.90 & 0.84 & 0.71 & 0.54 & 0.41 & 0.31 \\
$55-64$ & 0.77 & 0.77 & 0.73 & 0.70 & 0.64 & 0.53 & 0.42 & 0.32 & 0.24 \\
$65-74$ & 0.00 & 0.06 & 0.06 & 0.08 & 0.09 & 0.08 & 0.06 & 0.04 & 0.03 \\
$75+$ & 0.00 & 0.12 & 0.09 & 0.11 & 0.10 & 0.09 & 0.07 & 0.05 & 0.04 \\
\hline
\end{tabular}

(B) Tax Reform $\left(\tau_{a}\right)+\mathrm{SS}$

Baseline + SS Reform

\begin{tabular}{cccccccccc}
\hline \hline & \multicolumn{10}{c}{ Productivity group } \\
\cline { 2 - 11 } & $z_{1}$ & $z_{2}$ & $z_{3}$ & $z_{4}$ & $z_{5}$ & $z_{6}$ & $z_{7}$ & $z_{8}$ & $z_{9}$ \\
\cline { 2 - 10 } $20-25$ & 0.97 & 0.97 & 0.95 & 0.94 & 0.96 & 0.97 & 0.97 & 0.96 & 0.94 \\
$25-34$ & 0.98 & 0.98 & 0.96 & 0.95 & 0.94 & 0.93 & 0.88 & 0.77 & 0.59 \\
$35-44$ & 0.98 & 0.98 & 0.96 & 0.93 & 0.90 & 0.83 & 0.67 & 0.45 & 0.34 \\
$45-54$ & 0.98 & 0.98 & 0.96 & 0.93 & 0.89 & 0.78 & 0.60 & 0.46 & 0.35 \\
$55-64$ & 0.99 & 0.98 & 0.97 & 0.95 & 0.92 & 0.81 & 0.65 & 0.50 & 0.38 \\
$65-74$ & 1.00 & 1.00 & 0.99 & 0.98 & 0.96 & 0.87 & 0.71 & 0.56 & 0.43 \\
$75+$ & 1.00 & 1.00 & 1.00 & 1.00 & 0.99 & 0.94 & 0.81 & 0.66 & 0.52 \\
\hline
\end{tabular}

(c) Tax Reform $\left(\tau_{c}\right)$

Baseline + Tau C

\begin{tabular}{cccccccccc}
\hline \hline & \multicolumn{10}{c}{ Productivity group } \\
\cline { 2 - 11 } Age & $z_{1}$ & $z_{2}$ & $z_{3}$ & $z_{4}$ & $z_{5}$ & $z_{6}$ & $z_{7}$ & $z_{8}$ & $z_{9}$ \\
\cline { 2 - 11 } $20-25$ & 0.98 & 0.98 & 0.98 & 0.97 & 0.98 & 0.98 & 0.98 & 0.97 & 0.95 \\
$25-34$ & 0.99 & 0.99 & 0.98 & 0.98 & 0.96 & 0.94 & 0.90 & 0.79 & 0.61 \\
$35-44$ & 0.99 & 0.99 & 0.98 & 0.96 & 0.93 & 0.85 & 0.68 & 0.45 & 0.34 \\
$45-54$ & 0.94 & 0.93 & 0.91 & 0.87 & 0.79 & 0.66 & 0.49 & 0.36 & 0.27 \\
$55-64$ & 0.43 & 0.42 & 0.39 & 0.35 & 0.30 & 0.24 & 0.18 & 0.14 & 0.10 \\
$65-74$ & 0.00 & 0.00 & 0.00 & 0.00 & 0.00 & 0.00 & 0.00 & 0.00 & 0.00 \\
$75+$ & 0.00 & 0.00 & 0.00 & 0.00 & 0.00 & 0.00 & 0.00 & 0.00 & 0.00 \\
\hline
\end{tabular}


TABle XXV - Benchmark vs. Wealth Tax Economy

\begin{tabular}{cccccc}
\hline \multicolumn{5}{c}{ Wealth Taxes $\left(\tau_{a}\right)$} \\
\hline & P10 & P50 & P90 & P95 & P99 \\
\hline \multicolumn{5}{c}{ Before-tax } \\
\hline Benchmark & 2.00 & 2.00 & 17.28 & 22.35 & 42.36 \\
Wealth tax & 1.74 & 1.74 & 14.62 & 19.04 & 36.91 \\
Wealth tax and SS & 2.05 & 2.05 & 15.35 & 19.94 & 39.24 \\
Cons.tax & 1.07 & 1.07 & 13.18 & 17.30 & 33.36 \\
\hline & 1.50 & 1.50 & 12.96 & 16.76 & 31.77 \\
Benchmark & 0.59 & 0.59 & 13.32 & 17.69 & 35.35 \\
$\quad$ Wealth tax & 0.48 & 0.48 & 13.57 & 18.09 & 37.09 \\
Wealth tax and SS & \multicolumn{5}{c}{ After-tax }
\end{tabular}

Figure ?? shows the welfare gains for newborn agents (age 1) for three ability groups - the lowest, median, and highest - as a function of wealth. For the lowest and median entrepreneurial abilities, welfare gains decline monotonically with wealth. However, note that for low asset values, the welfare gain is positive. The black diamond on the $\mathrm{x}$-axis shows the average wealth of each group. For the person with average wealth, the welfare gain from switching to a wealth tax is positive. For the agents with the highest ability, the welfare gains are quite large. Welfare gains decline with wealth for high levels of wealth. However, it still remains positive for all wealth levels observed among one-year olds in the capital income tax steady state.

Table XXIII shows the average welfare gains by age group and entrepreneurial ability computed using the stationary distribution under the capital income tax. As evident from the table, in general, the highest two ability groups have higher welfare gains as expected. Since their tax liability will be shared with lower ability households, they earn a higher return on their capital. However, we also observe that households with low abilities have high welfare gains as well. These households do not accumulate much wealth since they have a low rate of return, and as a result their primary income source is labor income. However, note that when we switch to a wealth tax, the wage rate increases due to higher labor demand. Therefore, households who have low abilities do not lose much from the higher tax burden of the wealth tax system, but they enjoy a higher labor 


\begin{tabular}{|c|c|c|c|c|c|c|c|c|c|}
\hline \multicolumn{10}{|c|}{$\%$ Change in Types in Top $\mathrm{x} \%$ Wealth Group } \\
\hline Top x\% & $z_{1}$ & $z_{2}$ & $z_{3}$ & $z_{4}$ & $z_{5}$ & $z_{6}$ & $z_{7}$ & $z_{8}$ & $z_{9}$ \\
\hline 1 & -14.81 & -11.65 & -10.00 & -14.98 & -10.80 & 12.59 & 10.86 & 6.52 & 17.39 \\
\hline 5 & -5.12 & -4.81 & -9.89 & -6.93 & 1.58 & 9.85 & 8.58 & 6.35 & 3.23 \\
\hline 10 & -4.30 & -4.52 & -8.35 & -3.90 & 2.90 & 7.48 & 6.61 & 5.12 & 0.00 \\
\hline 50 & -3.28 & -3.67 & -3.83 & 0.57 & 1.76 & 1.46 & 1.08 & 1.17 & 0.00 \\
\hline
\end{tabular}

(A) Tax Reform from $\tau_{k}$ to $\tau_{a}$ : Change in Wealth Composition

\begin{tabular}{crrrrrrrrr}
\hline \hline \multicolumn{10}{c}{$\%$ Change in Types in Top x\% Wealth Group } \\
\hline Top x\% & \multicolumn{1}{c}{$z_{1}$} & \multicolumn{1}{c}{$z_{2}$} & \multicolumn{1}{c}{$z_{3}$} & \multicolumn{1}{c}{$z_{4}$} & \multicolumn{1}{c}{$z_{5}$} & \multicolumn{1}{c}{$z_{6}$} & $z_{7}$ & $z_{8}$ & \multicolumn{1}{c}{$z_{9}$} \\
\cline { 2 - 10 } 1 & -12.76 & -11.21 & -9.91 & -15.51 & -11.99 & 13.30 & 11.81 & 6.39 & 13.04 \\
5 & -4.83 & -4.58 & -10.15 & -7.04 & 1.48 & 10.20 & 8.91 & 6.45 & 3.23 \\
10 & -4.72 & -4.61 & -9.16 & -3.96 & 3.01 & 7.94 & 6.86 & 4.79 & 3.13 \\
50 & -4.34 & -4.83 & -4.45 & 0.74 & 2.10 & 1.54 & 0.63 & 1.14 & -2.38 \\
\hline
\end{tabular}

(в) Tax Reform from $\tau_{k}$ to $\tau_{a}$ and social security reform: Change in Wealth Composition

\begin{tabular}{|c|c|c|c|c|c|c|c|c|c|}
\hline \multicolumn{10}{|c|}{ \% Change in Types in Top x\% Wealth Group } \\
\hline Top x\% & $z_{1}$ & $z_{2}$ & $z_{3}$ & $z_{4}$ & $z_{5}$ & $z_{6}$ & $z_{7}$ & $z_{8}$ & $z_{9}$ \\
\hline 1 & -13.99 & -11.43 & -8.85 & -11.88 & -7.17 & 9.43 & 8.10 & 4.84 & 4.35 \\
\hline 5 & -7.73 & -7.43 & -10.07 & -6.50 & 2.31 & 8.66 & 7.73 & 5.59 & 3.23 \\
\hline 10 & -6.45 & -5.93 & -7.57 & -3.72 & 3.11 & 6.48 & 5.80 & 3.63 & 0.00 \\
\hline 50 & -2.26 & -2.63 & -2.61 & 0.38 & 1.14 & 1.29 & 1.16 & 1.05 & 0.00 \\
\hline
\end{tabular}

(c) Tax Reform from $\tau_{k}$ to $\tau_{c}$ : Change in Wealth Composition

For this we compute the shares under $\tau_{k}$ and under $\tau_{a}$ and get the percentage change of the shares (not the difference).

income. Households with $z_{3}$ and $z_{4}$ have the lowest welfare gains: for the youngest age group, welfare gains are 6.8 percent. These are the groups who accumulate relatively more wealth compared to lower ability groups. Since they obtain a lower after-tax return under the wealth tax, they gain the least.

Table XXIV shows the fraction of individuals with a positive welfare gain from the tax reform, by age group and entrepreneurial ability.

Table XXVII summarizes the results from the welfare analysis. The average welfare 
TABLE XXVI - Tax Reform from $\tau_{k}$ to $\tau_{a}$ : Wealth holdings at the top

\begin{tabular}{ccccccc}
\hline \hline \multicolumn{7}{c}{ Wealth Holdings of the top x\% } \\
\hline Top x\% & Data & Data $(>0)$ & $\tau_{k}$ & $\tau_{a}$ & $\tau_{a}+S S$ & $\tau_{c}$ \\
\cline { 2 - 7 } $0.01 \%$ & 6.32 & 6.24 & 13.26 & 19.82 & 21.50 & 17.07 \\
$0.1 \%$ & 14.33 & 13.40 & 22.54 & 31.82 & 34.09 & 28.27 \\
$0.5 \%$ & 27.21 & 25.45 & 31.19 & 41.48 & 43.82 & 37.93 \\
$1 \%$ & 35.79 & 33.64 & 35.89 & 46.09 & 48.37 & 42.70 \\
$10 \%$ & 74.98 & 71.85 & 65.18 & 71.57 & 73.17 & 69.19 \\
\hline
\end{tabular}

The data comes from Vermuelen (2016).

TABLE XXVII - Welfare

\begin{tabular}{|c|c|c|c|c|c|c|}
\hline & \multicolumn{2}{|c|}{ Tax Reform $\left(\tau_{a}\right)$} & \multicolumn{2}{|c|}{ Tax Reform $\left(\tau_{a}\right)+\mathrm{SS}$} & \multicolumn{2}{|c|}{ Tax Reform $\left(\tau_{c}\right)$} \\
\hline & CE1 & CE2 & CE1 & CE2 & CE1 & CE2 \\
\hline Av. welfare gains - newborns & 7.40 & 7.86 & 5.45 & 4.71 & 8.02 & 10.29 \\
\hline Average welfare gains & 3.14 & 5.14 & 4.95 & 4.10 & 1.91 & 6.89 \\
\hline Fraction in favor & \multicolumn{2}{|c|}{67.8} & \multicolumn{2}{|c|}{94.8} & \multicolumn{2}{|c|}{60.3} \\
\hline
\end{tabular}

gain is 5.14 percent. The average welfare gain for newborns is higher at 7.86 percent. Overall, 68 percent of all households across the whole population in the benchmark economy prefer to be in an economy with a wealth tax.

\subsection{Optimal Taxation}

The discussion so far illustrates that a wealth tax is better way of taxing capital than a capital income tax. A natural question, however, is whether taxing capital in this framework would be a part of the optimal tax schedule to begin with. We study quantitatively this question by performing two experiments: (i) we find the optimal taxes in an environment where the government uses proportional labor income taxes and proportional capital income taxes, and (ii) we find the optimal taxes in an environment where the government uses proportional labor income taxes and proportional wealth taxes. Table ?? shows that the optimal capital income tax is $-34.4 \%$, with a corresponding labor income tax of $36 \%$ while the optimal wealth tax is $3.06 \%$, with a corresponding labor income tax of $14.1 \%$. The optimal wealth tax delivers the highest welfare gain while under the optimal capital income tax the welfare gain is lower than in tax reform experiment. These results can be intuitively explained using the information provided 
in Figure ?? and the lower panel of Table ??.

\section{Figure 14 - Optimal Taxes}

(A) Welfare Gain from Optimal Taxes

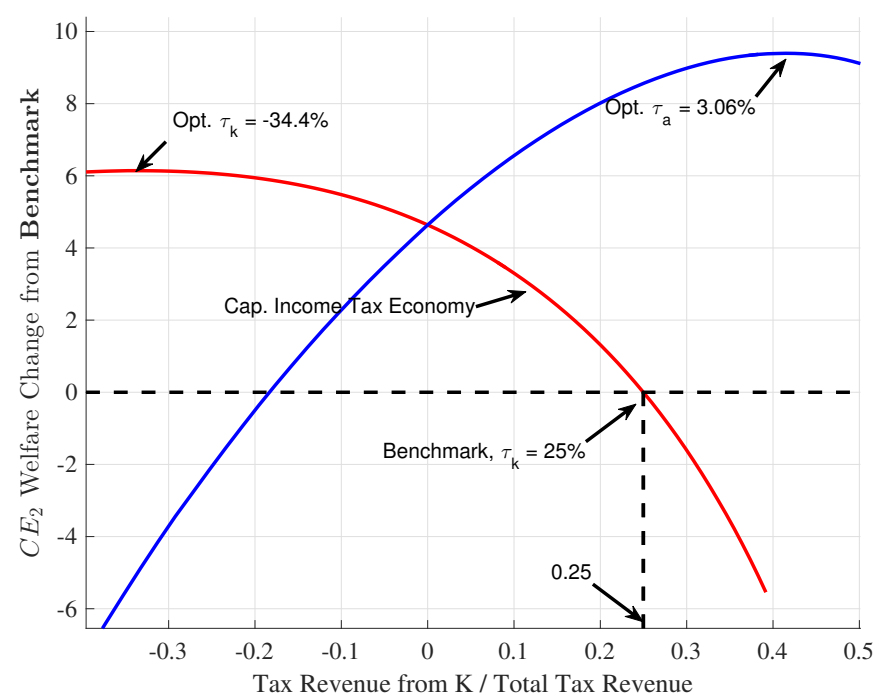

(B) Efficiency Gains from Optimal Taxes

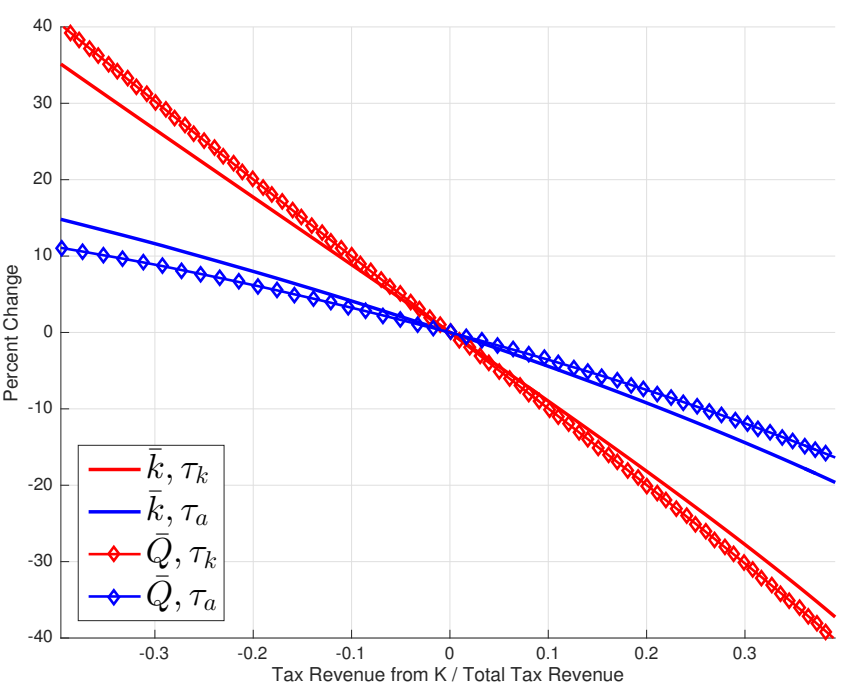

Figure 15 - Optimal Taxes

(A) Welfare gain at age 20 - Optimal capital tax

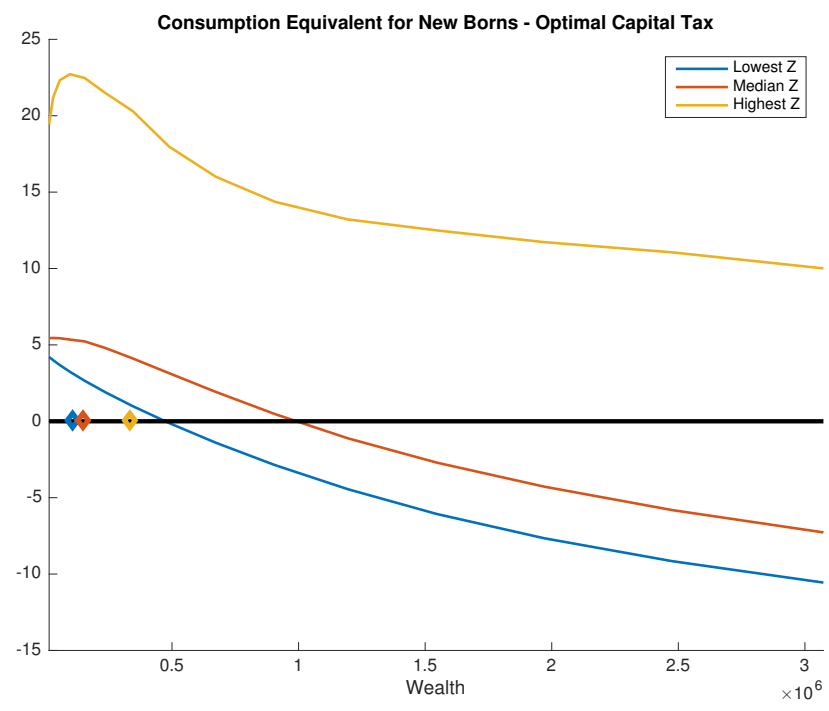

(в) Welfare gain at age 20 - Optimal wealth tax

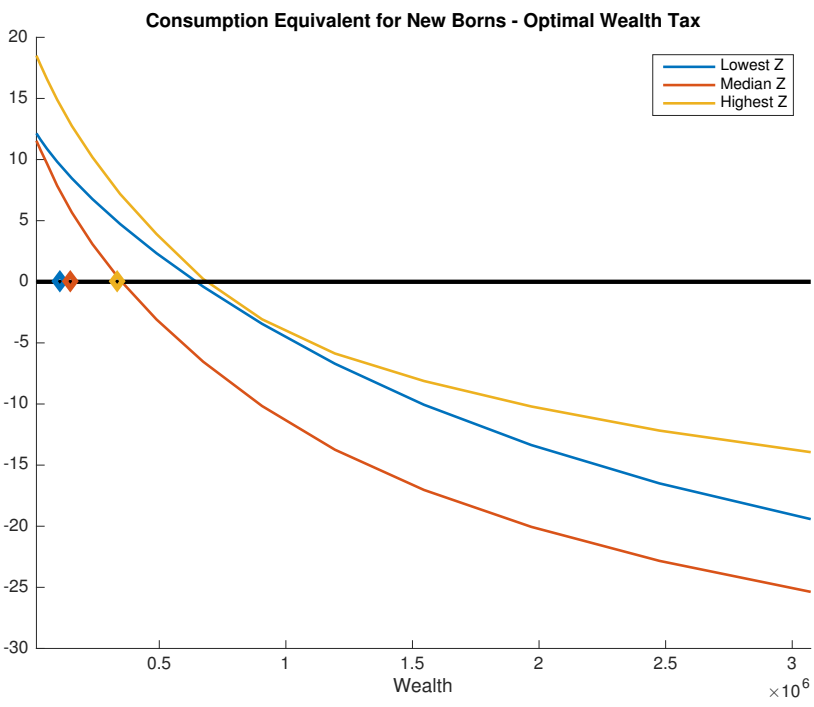

The vote share results in Table XXVIII should be taken as suggestive because they are comparisons across steady states. Notice that the optimal capital tax requires a much higher capital/output ratio, which requires a large amount of saving during a transition, 
Figure 16 - Optimal Taxes

(A) Diff. in saving rate - Age 20 - Opt. capital tax

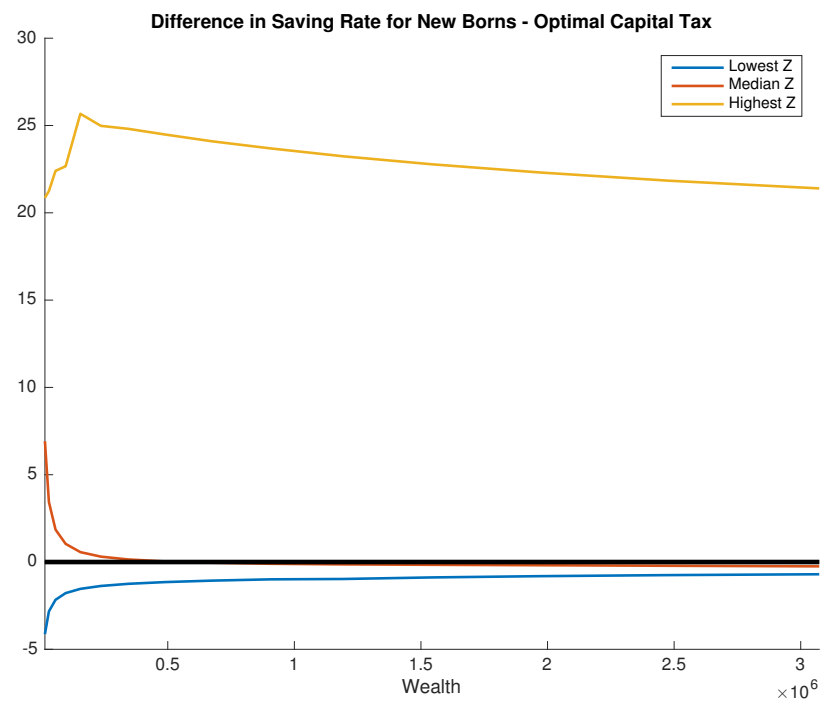

(c) Diff. in saving rate - Age 26 - Opt.capital tax

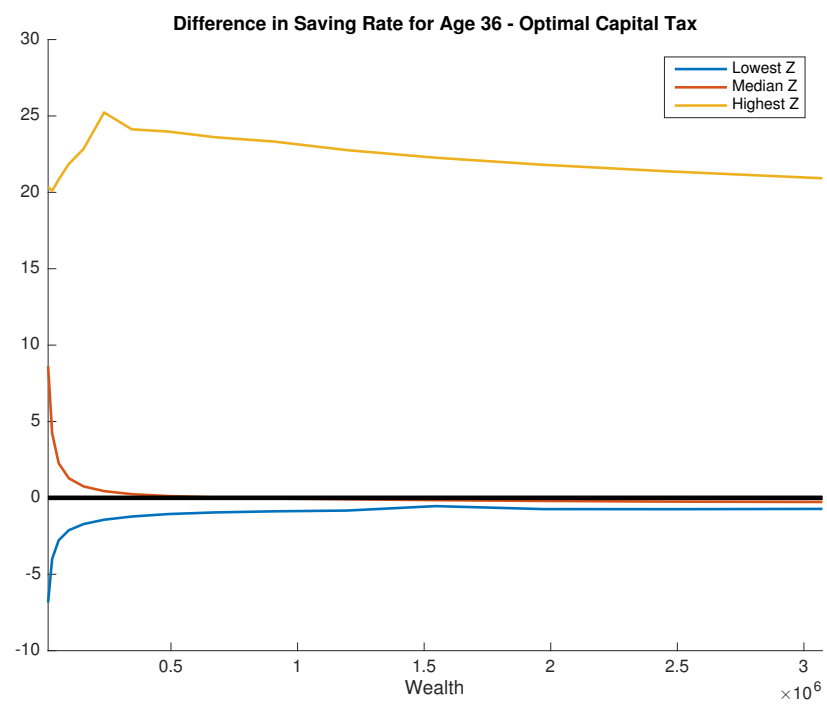

(B) Diff. in saving rate - Age 20 - Opt.wealth tax

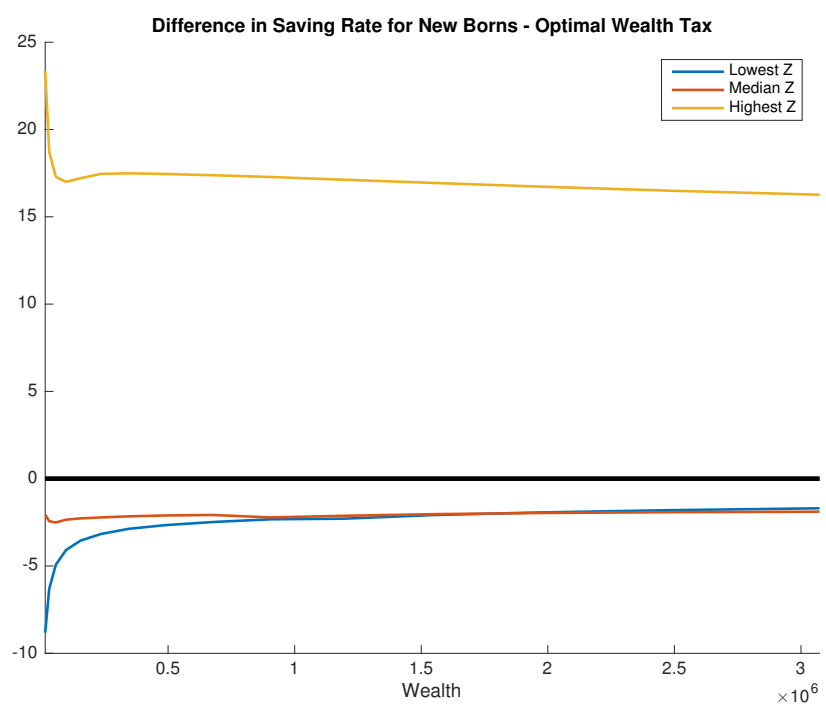

(D) Diff. in saving rate - Age 36 - Opt.wealth tax

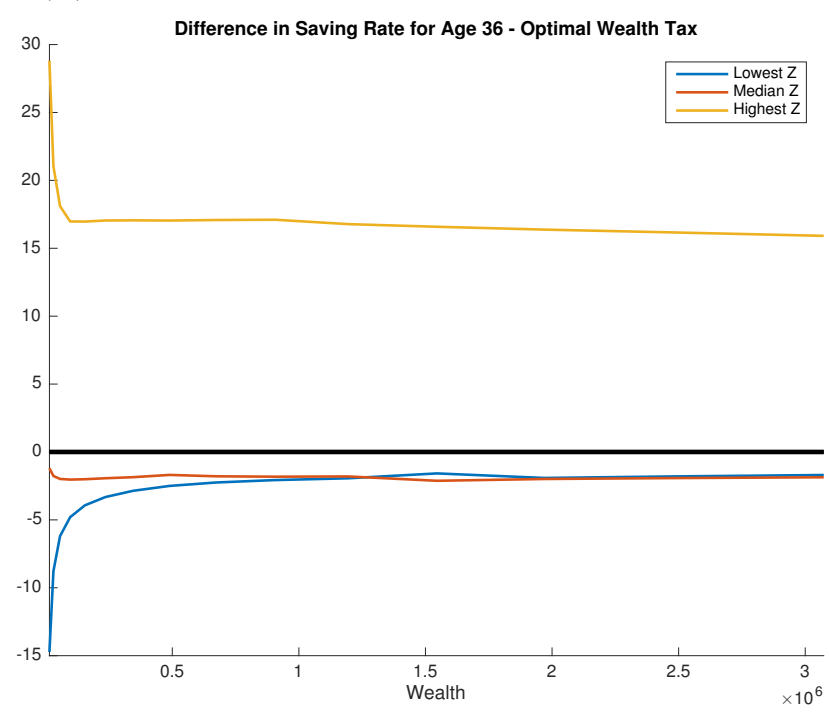

TABLE XXVIII - Optimal taxation: statistics

Baseline

\begin{tabular}{lcccccccccc}
\hline \hline & $\tau_{k}$ & $\tau_{\ell}$ & $\tau_{a}$ & $\frac{\text { Threshold }}{Y_{a}}$ & \%Taxed & $\bar{k} / Y$ & Top 1\% & Top 10\% & $\overline{C E}_{2}(\%)$ & Vote (\%) \\
\hline Benchmark & $25 \%$ & $22.4 \%$ & - & - & $100 \%$ & 3.0 & 0.36 & 0.66 & - & - \\
Tax reform & - & $22.4 \%$ & $1.13 \%$ & 0 & $100 \%$ & 3.25 & 0.46 & 0.72 & 7.86 & 67.8 \\
Opt. $\tau_{k}$ & $-34.4 \%$ & $36.0 \%$ & - & - & $100 \%$ & 4.04 & 0.56 & 0.79 & 6.28 & 69.7 \\
Opt. $\tau_{a}$ & - & $14.1 \%$ & $3.06 \%$ & 0 & $100 \%$ & 2.90 & 0.4736 & 0.7465 & 9.61 & 60.7 \\
\hline Opt. $\tau_{a}$-Threshold & - & $14.2 \%$ & $3.30 \%$ & $6.3 \%$ & $63 \%$ & 2.86 & 0.4764 & 0.74364 & 9.83 & 78.9
\end{tabular}


which would reduce the welfare benefits and hence the support for the reform. In contrast, the optimal wealth tax implies a lower capital/output ratio and hence dissaving, so there should be little to no loss during the transition (this is a conjecture!).

TABLE XXIX - Optimal taxation: Change in variables

\begin{tabular}{llrlrlllll} 
Baseline & \multicolumn{10}{c}{$\Delta K$} & \multicolumn{1}{c}{$\Delta Q$} & \multicolumn{1}{c}{$\Delta L$} & \multicolumn{1}{c}{$\Delta Y$} & $\Delta w$ & $\Delta w($ net $)$ & \multicolumn{1}{c}{$\Delta r$} & \multicolumn{1}{c}{$\Delta r($ net $)$} & $\Delta T F P$ \\
\hline \hline & 19.37 & 24.79 & 1.28 & 10.10 & 8.70 & 8.70 & -0.25 & -0.90 & 4.60 \\
Tax reform & 68.97 & 79.57 & -1.16 & 25.51 & 26.97 & 4.72 & -1.51 & -0.87 & 6.29 \\
Opt. $\tau_{k}$ & 2.76 & 10.26 & 3.90 & 6.40 & 2.41 & 13.42 & 0.68 & -1.92 & 7.29 \\
Opt. $\tau_{a}$ & 0.41 & 8.12 & 3.67 & 5.42 & 1.70 & 12.48 & 0.78 & -2.07 & 7.70 \\
\hline Opt. $\tau_{a}$-Threshold & & & & & & & & &
\end{tabular}

\subsubsection{Welfare Decomposition}

TABLE XXX - Welfare Gain by Age Group and Entrepreneurial Ability - Optimal Capital Taxes

\begin{tabular}{cccccccccc}
\multicolumn{10}{c}{ Optimal Capital Taxes } \\
\hline \hline \multirow{2}{*}{ Age } & \multicolumn{10}{c}{ Productivity group } \\
\cline { 2 - 11 } $20-25$ & $z_{1}$ & $z_{2}$ & $z_{3}$ & $z_{4}$ & $z_{5}$ & \multicolumn{1}{c}{$z_{6}$} & \multicolumn{1}{c}{} & \multicolumn{1}{c}{$z_{8}$} & \multicolumn{1}{c}{$z_{9}$} \\
\cline { 2 - 11 } $25-34$ & 3.7 & 3.6 & $\mathbf{3 . 7}$ & $\mathbf{4 . 9}$ & $\mathbf{7 . 1}$ & $\mathbf{1 0 . 7}$ & $\mathbf{1 4 . 8}$ & $\mathbf{1 6 . 7}$ & $\mathbf{1 7 . 1}$ \\
$35-44$ & 2.9 & 2.8 & 2.7 & 3.4 & 4.1 & 4.7 & 3.8 & 1.5 & -0.6 \\
$45-54$ & 2.1 & 2.0 & 1.9 & 2.4 & 2.7 & 2.6 & 1.0 & -1.1 & -3.2 \\
$55-64$ & 0.7 & 0.7 & 0.6 & 1.0 & 1.2 & 1.0 & -0.2 & -2.0 & -3.9 \\
$65-74$ & -0.3 & -0.3 & -0.3 & 0.0 & 0.2 & 0.1 & -0.7 & -2.0 & -3.5 \\
$75+$ & -0.1 & -0.1 & -0.1 & 0.1 & 0.2 & 0.2 & -0.3 & -1.0 & -1.9 \\
\hline
\end{tabular}


TABLE XXXI - Fraction with Positive Welfare Gain by Age Group and Entrepreneurial Ability - Optimal Capital Taxes

Optimal Capital Taxes

\begin{tabular}{cccccccccc}
\hline \hline & \multicolumn{10}{c}{ Productivity group } \\
\cline { 2 - 10 } Age & $z_{1}$ & $z_{2}$ & $z_{3}$ & $z_{4}$ & $z_{5}$ & $z_{6}$ & $z_{7}$ & $z_{8}$ & $z_{9}$ \\
\cline { 2 - 10 } $20-25$ & 0.96 & 0.95 & 0.95 & 0.98 & 0.99 & 0.99 & 0.99 & 0.99 & 0.99 \\
$25-34$ & 0.97 & 0.97 & 0.96 & 0.98 & 0.97 & 0.96 & 0.94 & 0.90 & 0.85 \\
$35-44$ & 0.95 & 0.94 & 0.92 & 0.95 & 0.93 & 0.88 & 0.80 & 0.68 & 0.58 \\
$45-54$ & 0.88 & 0.88 & 0.86 & 0.89 & 0.85 & 0.78 & 0.66 & 0.53 & 0.43 \\
$55-64$ & 0.68 & 0.67 & 0.68 & 0.72 & 0.69 & 0.62 & 0.52 & 0.41 & 0.31 \\
$65-74$ & 0.09 & 0.05 & 0.14 & 0.22 & 0.22 & 0.21 & 0.18 & 0.15 & 0.11 \\
$75+$ & 0.12 & 0.12 & 0.13 & 0.15 & 0.15 & 0.15 & 0.13 & 0.11 & 0.09 \\
\hline
\end{tabular}

TABle XXXII - Welfare Gain by Age Group and Entrepreneurial Ability - Optimal Wealth Taxes

Optimal Wealth Taxes

\begin{tabular}{crrrrrrrrr}
\hline & \multicolumn{10}{c}{ Productivity group } \\
\cline { 2 - 10 } Age & \multicolumn{1}{c}{$z_{1}$} & \multicolumn{1}{c}{$z_{2}$} & $z_{3}$ & $z_{4}$ & $z_{5}$ & \multicolumn{1}{c}{$z_{6}$} & \multicolumn{1}{c}{$z_{7}$} & \multicolumn{1}{c}{$z_{9}$} \\
\cline { 2 - 10 } & $\mathbf{1 1 . 0}$ & $\mathbf{1 0 . 7}$ & $\mathbf{9 . 9}$ & $\mathbf{9 . 1}$ & $\mathbf{9 . 2}$ & $\mathbf{1 0 . 3}$ & $\mathbf{1 2 . 1}$ & $\mathbf{1 2 . 4}$ & $\mathbf{1 1 . 3}$ \\
$25-34$ & 10.5 & 10.2 & 9.1 & 7.7 & 6.6 & 5.7 & 4.3 & -0.1 & -5.5 \\
$35-44$ & 8.9 & 8.6 & 7.5 & 5.8 & 4.1 & 1.7 & -2.4 & -8.2 & -13.1 \\
$45-54$ & 6.5 & 6.3 & 5.4 & 3.9 & 2.3 & -0.3 & -4.6 & -9.3 & -13.2 \\
$55-64$ & 2.5 & 2.4 & 1.8 & 0.9 & -0.1 & -2.1 & -5.4 & -9.1 & -12.3 \\
$65-74$ & -0.7 & -0.7 & -0.9 & -1.3 & -1.8 & -3.0 & -5.3 & -7.9 & -10.4 \\
$75+$ & -0.1 & -0.1 & -0.2 & -0.3 & -0.6 & -1.3 & -2.7 & -4.5 & -6.2 \\
\hline
\end{tabular}


TABLE XXXIII - Fraction with Positive Welfare Gain by Age Group and Entrepreneurial Ability - Optimal WealthTaxes

Optimal Wealth Taxes

\begin{tabular}{cccccccccc}
\hline \hline & \multicolumn{10}{c}{ Productivity group } \\
\cline { 2 - 10 } Age & $z_{1}$ & $z_{2}$ & $z_{3}$ & $z_{4}$ & $z_{5}$ & $z_{6}$ & $z_{7}$ & $z_{8}$ & $z_{9}$ \\
\cline { 2 - 10 } $20-25$ & 0.97 & 0.97 & 0.95 & 0.93 & 0.93 & 0.94 & 0.93 & 0.90 & 0.87 \\
$25-34$ & 0.98 & 0.98 & 0.96 & 0.93 & 0.90 & 0.86 & 0.77 & 0.59 & 0.43 \\
$35-44$ & 0.97 & 0.97 & 0.94 & 0.87 & 0.80 & 0.66 & 0.48 & 0.35 & 0.27 \\
$45-54$ & 0.93 & 0.93 & 0.88 & 0.79 & 0.68 & 0.55 & 0.42 & 0.32 & 0.25 \\
$55-64$ & 0.73 & 0.72 & 0.67 & 0.59 & 0.51 & 0.41 & 0.33 & 0.25 & 0.19 \\
$65-74$ & 0.00 & 0.02 & 0.01 & 0.02 & 0.01 & 0.01 & 0.01 & 0.00 & 0.00 \\
$75+$ & 0.00 & 0.00 & 0.04 & 0.03 & 0.02 & 0.02 & 0.01 & 0.01 & 0.00 \\
\hline
\end{tabular}

TABLE XXXIV - Welfare Gain by Age Group and Entrepreneurial Ability - Optimal Wealth Taxes with Threshold

Optimal Wealth Taxes with Threshold

\begin{tabular}{crrrrrrrrr}
\hline \hline & \multicolumn{10}{c}{ Productivity group } \\
\cline { 2 - 10 } Age & \multicolumn{1}{c}{$z_{1}$} & \multicolumn{1}{c}{$z_{2}$} & $z_{3}$ & $z_{4}$ & $z_{5}$ & \multicolumn{1}{c}{$z_{6}$} & \multicolumn{1}{c}{$z_{7}$} & \multicolumn{1}{c}{$z_{8}$} & $z_{9}$ \\
\cline { 2 - 10 } $20-25$ & $\mathbf{1 0 . 5}$ & $\mathbf{1 0 . 3}$ & $\mathbf{9 . 8}$ & $\mathbf{9 . 3}$ & $\mathbf{9 . 5}$ & $\mathbf{1 0 . 6}$ & $\mathbf{1 2 . 4}$ & $\mathbf{1 2 . 6}$ & $\mathbf{1 1 . 4}$ \\
$25-34$ & 10.1 & 9.9 & 9.0 & 7.8 & 6.7 & 5.7 & 4.2 & -0.5 & -6.3 \\
$35-44$ & 8.6 & 8.4 & 7.4 & 5.8 & 4.1 & 1.5 & -2.8 & -9.0 & -14.2 \\
$45-54$ & 6.3 & 6.2 & 5.3 & 3.9 & 2.2 & -0.5 & -5.1 & -10.0 & -14.2 \\
$55-64$ & 2.5 & 2.4 & 1.9 & 1.0 & 0.0 & -2.1 & -5.7 & -9.6 & -13.0 \\
$65-74$ & -0.5 & -0.5 & -0.6 & -1.0 & -1.5 & -2.8 & -5.3 & -8.2 & -10.9 \\
$75+$ & -0.1 & -0.1 & -0.1 & -0.2 & -0.4 & -1.1 & -2.7 & -4.7 & -6.5 \\
\hline
\end{tabular}


TABLE XXXV - Fraction with Positive Welfare Gain by Age Group and Entrepreneurial Ability - Optimal Wealth Taxes with Threshold

\begin{tabular}{|c|c|c|c|c|c|c|c|c|c|}
\hline \multirow[b]{2}{*}{ Age } & \multicolumn{9}{|c|}{ Productivity group } \\
\hline & $z_{1}$ & $z_{2}$ & $z_{3}$ & $z_{4}$ & $z_{5}$ & $z_{6}$ & $z_{7}$ & $z_{8}$ & $z_{9}$ \\
\hline $20-25$ & 0.97 & 0.97 & 0.95 & 0.93 & 0.93 & 0.94 & 0.93 & 0.90 & 0.86 \\
\hline $25-34$ & 0.98 & 0.98 & 0.96 & 0.93 & 0.90 & 0.85 & 0.77 & 0.57 & 0.42 \\
\hline $35-44$ & 0.97 & 0.97 & 0.94 & 0.87 & 0.79 & 0.66 & 0.48 & 0.35 & 0.27 \\
\hline $45-54$ & 0.93 & 0.92 & 0.87 & 0.79 & 0.68 & 0.55 & 0.42 & 0.32 & 0.25 \\
\hline $55-64$ & 0.79 & 0.78 & 0.74 & 0.65 & 0.56 & 0.46 & 0.36 & 0.28 & 0.21 \\
\hline $65-74$ & 0.70 & 0.63 & 0.65 & 0.57 & 0.49 & 0.42 & 0.34 & 0.26 & 0.20 \\
\hline $75+$ & 0.93 & 0.92 & 0.90 & 0.84 & 0.78 & 0.68 & 0.55 & 0.43 & 0.34 \\
\hline
\end{tabular}

TABlE XXXVI - Decomposition of Welfare Gain - CE1

\begin{tabular}{ccccccc}
\hline & \multicolumn{2}{c}{ Tax Reform } & \multicolumn{2}{c}{ Opt. $\tau_{k}$} & \multicolumn{2}{c}{ Opt. $\tau_{a}$} \\
& NB & All & NB & All & NB & All \\
\hline$\overline{C E}_{1}$ & 7.40 & 3.14 & 5.55 & 2.38 & 10.03 & 3.61 \\
\hline Cons. & & & & & & \\
Total & 7.71 & 3.71 & 5.73 & 2.55 & 9.91 & 4.21 \\
Level & 10.48 & 10.01 & 16.88 & 21.04 & 10.59 & 8.28 \\
Dist. & -2.51 & -5.73 & -9.55 & -15.28 & -0.62 & -3.76 \\
\hline Leisure & & & & & & \\
Total & -0.29 & -0.55 & -0.17 & -0.17 & 0.09 & -0.59 \\
Level & -0.52 & -0.66 & 0.31 & 0.73 & -2.13 & -2.21 \\
Dist. & 0.23 & 0.10 & -0.50 & -0.90 & 2.22 & 1.59 \\
\hline
\end{tabular}

"NB" means new born and "All" is the whole population 
TABLE XXXVII - Decomposition of Welfare Gain - CE2

\begin{tabular}{ccccccc}
\hline & \multicolumn{2}{c}{ Tax Reform } & \multicolumn{2}{c}{ Opt. $\tau_{k}$} & \multicolumn{2}{c}{ Opt. $\tau_{a}$} \\
& NB & All & NB & All & NB & All \\
\hline$\overline{C E}_{2}$ & 7.86 & 5.14 & 6.28 & 4.87 & 9.61 & 4.79 \\
\hline Cons. & & & & & & \\
Total & 8.27 & 5.58 & 5.90 & 4.99 & 11.02 & 5.10 \\
Level & 10.48 & 10.01 & 16.88 & 21.04 & 10.59 & 8.28 \\
Dist. & -2.00 & -4.03 & -9.40 & -13.26 & 0.38 & -2.94 \\
\hline Leisure & & & & & & \\
Total & -0.38 & -0.61 & 0.36 & 1.10 & -1.27 & -2.54 \\
Level & -0.52 & -0.66 & 0.31 & 0.73 & -2.13 & -2.21 \\
Dist. & 0.13 & 0.02 & 0.04 & 0.41 & 0.67 & -0.69
\end{tabular}

"NB" means new born and "All" is the whole population 


\subsection{Misallocation in the Benchmark Economy}

Overview. Our benchmark economy is distorted due to the existence of financial frictions in the form of borrowing constraints, we can measure the effects of these distortions in aggregate TFP and output, and compare them to those obtained in other studies. A large and growing literature builds on Restuccia and Rogerson (2008) and frames the discussion on misallocation in terms of various wedges, such as capital, labor, and output wedges. The analysis in Hsieh and Klenow (2009) is particularly useful since, in a similar model environment, they study the degree of misallocation and its effect on TFP in manufacturing in China, India, and the United States. Hsieh and Klenow (2009) use detailed firm-level data from the US Census of Manufacturers (1977, 1082, 1987, 1992, and 1997) and find that the TFP gains from removing all distortions (wedges), which equalizes 'Revenue Productivity' (TFPR) within each industry, is 36\% in 1977, $31 \%$ in 1987 , and $43 \%$ in 1997.

We will follow the approach in Hsieh and Klenow (2009) and will compute the same measures of misallocation for the US as in their analysis. It is useful to briefly describe their approach as it applies to our framework. ${ }^{5}$ The final goods producer behaves competitively and uses an aggregated good, $Q$, and labor, $L$, in the production of the final good

$$
Y=Q^{\alpha} L^{1-\alpha}
$$

where $Q$ aggregates the intermediate goods $x_{i}$ in the following way

$$
Q=\left(\int_{i} x_{i}^{\mu} d i\right)^{1 / \mu}
$$

Each intermediate-goods producer $i$ produces a differentiated intermediate good using the production function $x_{i}=z_{i} k_{i}$, where $z_{i}$ is the individual $i$ 's entrepreneurial ability and $k_{i}$ is the amount of capital.

Instead of modeling and capturing the effect of a particular distortion, or distortions, the approach in Hsieh and Klenow (2009), and the related misallocation literature, is to infer the underlying distortions and wedges in the economy by studying the extent to which the marginal revenue products of capital and labor differ across firms in the economy (or in a particular industry). This is based on the insight that absent any

\footnotetext{
${ }^{5}$ Appendix A summarizes in great detail our benchmark model environment and the existing financial friction.
} 
distortions, the marginal revenue products of capital and labor have to be equalized across all firms. ${ }^{6}$

TFP in the $Q$ sector. We will first focus on the $Q$-sector, the sector that produces the aggregate good $Q$ by aggregating all the intermediate goods $x_{i}$ in that sector. Under this alternative capital-wedge approach, the problem of each intermediate-goods producer is

$$
\pi_{i}=\max _{k_{i}} p\left(z_{i} k_{i}\right) z_{i} k_{i}-\left(1+\tau_{i}^{k}\right)(R+\delta) k_{i}
$$

where $\tau_{i}^{k}$ is a firm-specific capital wedge. The only input in the production function of the intermediate-goods producer is capital, and as a result only one wedge can be identified in the analysis. We choose to specify that wedge to be the capital wedge, but in principle it should be understood as capturing the effect of an output wedge. Appendix A shows how the solution to the firm's problem changes as a function of the capital wedge $\tau_{i}^{k}$, as well as the derivation of the expressions that follow below.

The revenue TFP in sector $Q$ for each firm $i$ is

$$
\operatorname{TFPR}_{Q, i} \equiv \frac{p\left(x_{i}\right) x_{i}}{k_{i}}=\frac{1}{\mu}\left(1+\tau_{i}^{k}\right)(R+\delta)
$$

The aggregate TFP in sector $Q$ can be expressed as

$$
T F P_{Q}=\left(\int_{i}\left(z_{i} \frac{\overline{T F P R_{Q}}}{T F P R_{Q, i}}\right)^{\frac{\mu}{1-\mu}} d i\right)^{\frac{1-\mu}{\mu}}
$$

where the average $T F P R_{Q}$ is given by

$$
\overline{T F P R_{Q}}=\left(\int \frac{1}{T F P R_{Q, i}} \frac{p\left(x_{i}\right) x_{i}}{p_{q} Q} d i\right)^{-1} .
$$

In the non-distorted economy, without capital wedges, the level of TFP in the $Q$ sector is

$$
\operatorname{TFP}_{Q}^{*}=\left(\int_{i}\left(z_{i}\right)^{\frac{\mu}{1-\mu}} d i\right)^{\frac{1-\mu}{\mu}} \equiv \bar{z}
$$

\footnotetext{
${ }^{6}$ This is the case in the monopolistic competition models, such as in Hsieh and Klenow (2009). Alternatively, in environments such as in Lucas (1978) and Restuccia and Rogerson (2008), in which firms feature decreasing returns to scale, but produce the same homogeneous good, in the non-distorted economy the marginal products of capital and labor have to be equalized.
} 
Therefore, we can measure the improvement in TFP in the $Q$ sector, $\Omega_{Q}$, as a result of eliminating the capital wedges, or equivalently, as a result of eliminating the borrowing constraints:

$$
\Omega_{Q}=\frac{T F P_{Q}^{*}}{T F P_{Q}}=\left(\int_{i}\left(\frac{\bar{z}}{z_{i}} \frac{T F P R_{Q, i}}{\overline{T F P R_{Q}}}\right)^{\frac{\mu}{1-\mu}} d i\right)^{\frac{1-\mu}{\mu}} .
$$

Table XXXVIII reports $\Omega_{Q}$ for various economies - the TFP in the $Q$ sector in the nondistorted economy is $58 \%$ higher than in the benchmark economy, $51 \%$ higher than in the economy with a wealth tax, $54 \%$ higher than in the economy with consumption tax, $49 \%$ higher than in the economy with an optimal capital income tax, and $47 \%$ higher than in the economy with an optimal wealth tax.

Wealth taxes give the higher TFP gains, allowing for better allocation of capital across firms, even without eliminating the borrowing constraints. The tax reform experiment to wealth taxes implies a TFP gain of $4.6 \%$ and optimal wealth taxes give a TFP gain of $7.3 \%$ with respect to our benchmark economy.

This can also be seen in the dispersion of TFPR of the different models. Recall that absent any constraints on the firms the TFPR would be equated across all of them, so there is higher misallocation in the economy the higher the dispersion of TFPR across firms. Table XXXVIII reports the standard deviation of TFPR and some of its percentiles.

TABle XXXVIII - Hsieh and Klenow (2009) Efficiency Measure - Benchmark Model

\begin{tabular}{c|ccccc}
\multicolumn{1}{c|}{ Benchmark } & Tax Reform $\left(\tau_{a}\right)$ & Tax Reform $\left(\tau_{c}\right)$ & Opt. Taxes $\left(\tau_{k}\right)$ & Opt. Taxes $\left(\tau_{a}\right)$ \\
\hline \hline TFP & 1.001 & 1.047 & 1.027 & 1.064 & 1.074 \\
$\frac{T F P_{Q}^{*}}{T F P_{Q}}$ & 1.582 & 1.514 & 1.543 & 1.489 & 1.475 \\
\hline Mean TFPR & 0.145 & 0.131 & 0.12 & 0.106 & 0.145 \\
StD TFPR & 0.054 & 0.048 & 0.044 & 0.039 & 0.053 \\
\hline p99.99 & 0.94 & 0.85 & 0.8 & 0.69 & 0.91 \\
p99.9 & 0.68 & 0.61 & 0.58 & 0.5 & 0.66 \\
p99 & 0.35 & 0.32 & 0.3 & 0.27 & 0.35 \\
p95 & 0.23 & 0.2 & 0.19 & 0.17 & 0.23 \\
p90 & 0.19 & 0.17 & 0.16 & 0.14 & 0.19 \\
p75 & 0.16 & 0.14 & 0.13 & 0.11 & 0.16 \\
p50 & 0.14 & 0.12 & 0.11 & 0.1 & 0.14 \\
p25 & 0.12 & 0.11 & 0.1 & 0.09 & 0.12 \\
p10 & 0.1 & 0.09 & 0.08 & 0.07 & 0.1 \\
p1 & 0.08 & 0.07 & 0.07 & 0.06 & 0.09
\end{tabular}


Comparison with the Hsieh and Klenow (2009) results for the US. In order to compare these results with the results reported in Hsieh and Klenow (2009) for the US, we need to use equation (1) and note that the improvement in aggregate output, $\Omega_{Y}$, as a result of eliminating the capital wedges in the economy can be expressed as

$$
\Omega_{Y}=\frac{Y^{*}}{Y}=\left(\frac{T F P_{Q}^{*}}{T F P_{Q}}\right)^{\alpha}\left(\frac{K^{*}}{K}\right)^{\alpha}\left(\frac{L^{*}}{L}\right)^{1-\alpha} \text {. }
$$

Since the model with capital wedges is static, the effect of the removal of the capital wedges on aggregate capital, $K$, and labor supply, $L$ cannot be taken into account. The analysis in Hsieh and Klenow (2009), measures the improvement in total output as a result of an improvement in TFP in all industries. In our model, this corresponds to the improvement in TFP in the $Q$ sector. Therefore, removing the capital wedges would increase total output, through its effect on TFP in the $Q$ sector, by $20 \%{ }^{7}$

Two things are important to point out. First, the magnitude of the misallocation in our benchmark economy is substantial, although a bit lower than the one measured in Hsieh and Klenow (2009) using micro data from manufacturing firms: 36\% in 1977, 31\% in 1987, and $43 \%$ in 1997. Our benchmark economy is parametrized based on moments from the entire economy, not just the manufacturing sector. Second, our benchmark model is a dynamic model and any changes in the financial frictions will affect aggregate capital accumulation and aggregate labor supply. The misallocation calculations above do not take those changes into account. It is clear, however, that eliminating the financial friction would increase the aggregate capital stock $K$ and lead a larger increases in total output than measured above. The effect on aggregate labor supply is less obvious.

\footnotetext{
${ }^{7}$ Note that $\tilde{\Omega}_{Y}=\Omega_{Q}^{\alpha}=\Omega_{Q}^{0.40}=1.20$.
} 
FigURE 17 - Distribution of TFPR

(A) $\log \left(\mathrm{TFPR}_{i} / \overline{\mathrm{TFPR}}\right)-$ Tax Reform $\tau_{w}$

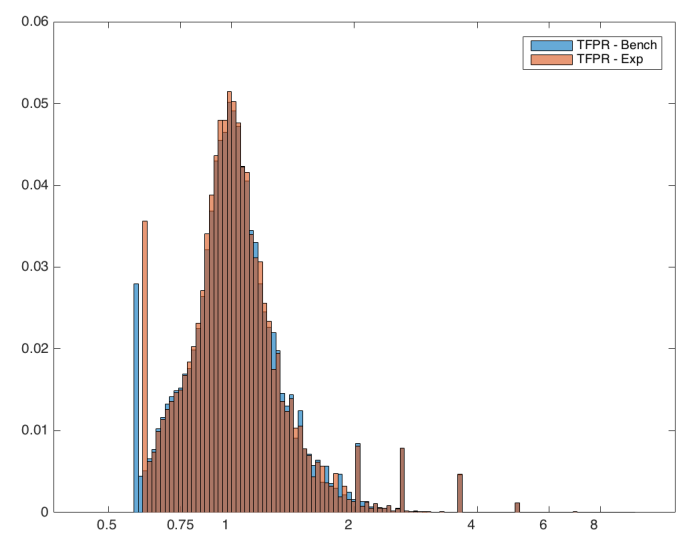

(C) $\log \left(\mathrm{TFPR}_{i} / \overline{\mathrm{TFPR}}\right)$ - Tax Reform $\tau_{c}$

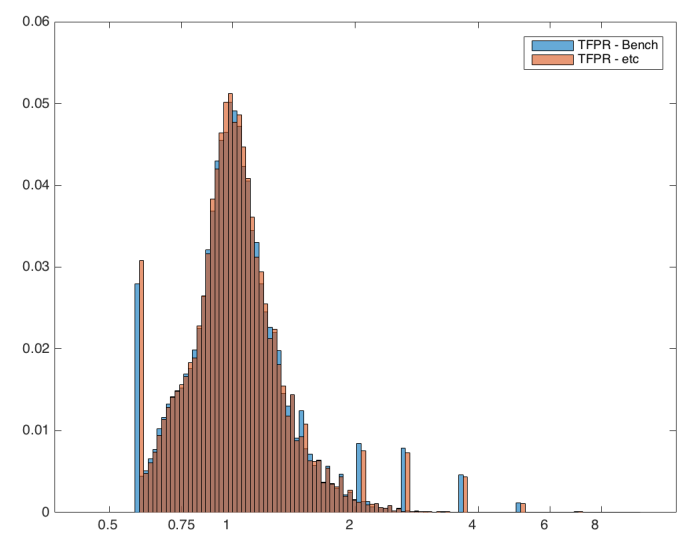

(B) $\log \left(\mathrm{TFPR}_{i} / \overline{\mathrm{TFPR}}\right)$ - NewBorns - Tax Reform $\tau_{w}$

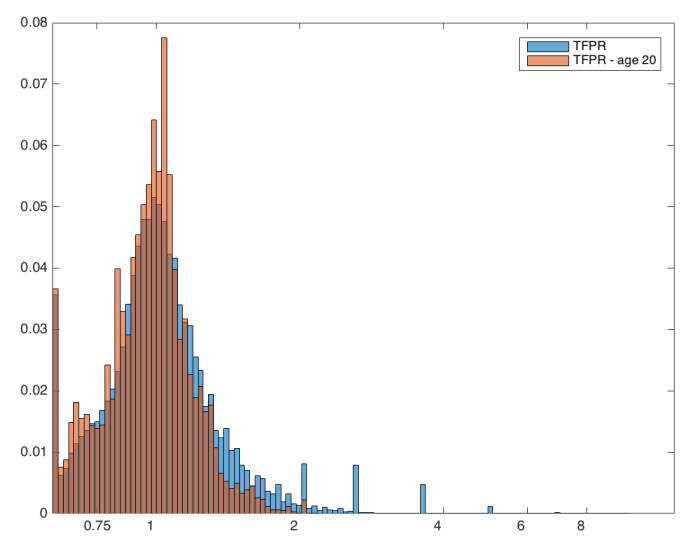

(D) $\log \left(\mathrm{TFPR}_{i} / \overline{\mathrm{TFPR}}\right)$ - NewBorns - Tax Reform $\tau_{c}$

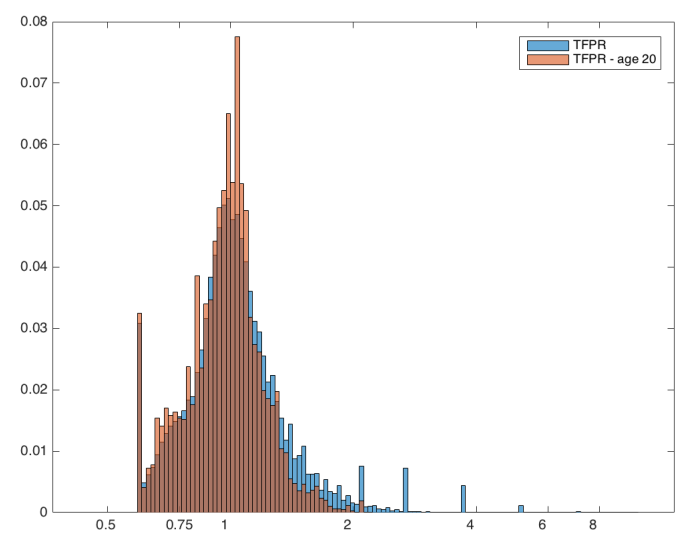

\section{Conclusions}

TO BE COMPLETED 


\section{References}

Aiyagari, Rao S., "Optimal Capital Income Taxation with Incomplete Markets, Borrowing Constraints, and Constant Discounting," Journal of Political Economy, 1995, 103 (6), 1158-1175.

Aiyagari, S Rao, "Uninsured Idiosyncratic Risk and Aggregate Saving," The Quarterly Journal of Economics, August 1994, 109 (3), 659-84.

Atkeson, Andrew, V. V. Chari, and Patrick J. Kehoe, "Taxing Capital Income: A Bad Idea," Federal Reserve Bank of Minneapolis Quarterly Review, 1999, 23 (3), $3-17$.

Benhabib, Jess, Alberto Bisin, and Shenghao Zhu, "The Distribution of Wealth and Fiscal Policy in Economies With Finitely Lived Agents," Econometrica, 2011, 79 (1), 123-157.

_, _, and _, "The Wealth Distribution in Bewley Models with Investment Risk," Working Paper, 2013.

_ , _, and _, "The Distribution of Wealth in the Blanchard-Yaari Model," Macroeconomic Dynamics, Forthcoming, 2014.

Buera, F., J. Kaboski, and Yongseok Shin, "Finance and Development: A Tale of Two Sectors," American Economic Review, August 2011, pp. 1964-2002.

Cagetti, Marco and Mariacristina De Nardi, "Entrepreneurship, Frictions, and Wealth," Journal of Political Economy, 2006, 114 (5), 835-869.

_ and _ , "Estate Taxation, Entrepreneurship, and Wealth," American Economic Review, 2009, 99 (1), 85-111.

Castañeda, Ana, Javier Díaz-Giménez, and José-Víctor Ríos-Rull, "Accounting for the U.S. Earnings and Wealth Inequality," The Journal of Political Economy, 2003, $111(4), 818-857$.

Chamley, Christophe, "Optimal Taxation of Capital Income in General Equilibrium with Infinite Lives," Econometrica, 1986, 54 (3), 607-622. 
Conesa, Juan Carlos, Sagiri Kitao, and Dirk Krueger, "Taxing capital? Not a bad idea after all!," American Economic Review, 2009, 99 (1), 25-48.

Diaz-Gimenez, Javier, Andy Glover, and Jose-Victor Rios-Rull, "Facts on the Distributions of Earnings, Income, and Wealth in the United States: 2007 Update," Quarterly Review, 2011, (Spr), 2-31.

Erosa, Andres and Martin Gervais, "Optimal Taxation in Life-Cycle Economies," Journal of Economic Theory, 2002, 105 (2), 338-369.

Gabaix, Xavier, "The Granular Origins of Aggregate Fluctuations," Econometrica, May 2011, 79-3, 733-772.

Garriga, Carlos, "Optimal Fiscal Policy in Overlapping Generations Models," mimeo, 2003.

Golosov, Mikhail, Narayana Kocherlakota, and Aleh Tsyvinski, "Optimal Indirect And Capital Taxation," Review of Economic Studies, 2003, 70 (3), 569-587.

Guvenen, Fatih, "Learning Your Earning: Are Labor Income Shocks Really Very Persistent?," American Economic Review, June 2007, 97 (3), 687-712.

Hubbard, R. Glenn, Kenneth L. Judd, Robert E. Hall, and Lawrence Summers, "Liquidity Constraints, Fiscal Policy, and Consumption," Brookings Papers on Economic Activity, 1986, 1986 (1), 1-59.

Huggett, Mark, "The Risk-Free Rate in Heterogeneous-Agent Incomplete-Insurance Economies," Journal of Economic Dynamics and Control, 1993, 17, 953-969.

Imrohoroglu, Selahattin, "A Quantitative Analysis of Capital Income Taxation," International Economic Review, 1998, 39, 307-328.

Jones, Larry E., Rodolfo E. Manuelli, and Peter E. Rossi, "Optimal Taxation in Models of Endogenous Growth," Journal of Political Economy, 1993, 101 (3), 485-517.

Judd, Kenneth L., "Redistributive Taxation in a Simple Perfect Foresight Model," Journal of Public Economics, 1985, 28 (1), 59-83.

Kitao, Sagiri, "Labor-Dependent Capital Income Taxation," Journal of Monetary Economics, 2010, 57 (8), 959-974. 
Kocherlakota, Narayana R., "Zero Expected Wealth Taxes: A Mirrlees Approach to Dynamic Optimal Taxation," Econometrica, 2005, 73 (5), 1587-1621.

Krusell, Per and Anthony A Smith, "Income and Wealth Heterogeneity in the Macroeconomy," Journal of Political Economy, 1998, 106 (5), 867-896.

Lucas, Robert E., "Supply-Side Economics: An Analytical Review," Oxford Economic Papers New Series, 1990, 42 (2), 293-316.

Piketty, Thomas, Capital in the Twenty-First Century, Cambridge: Belknap of Harvard UP, 2014.

Quadrini, Vincenzo, "Entrepreneurship, Saving, and Social Mobility," Review of Economic Dynamics, 2000, 3 (1), 1-40.

Shourideh, Ali, "Optimal Taxation of Wealthy Individuals," Technical Report, Wharton School at University of Pennsylvania 2012.

Storesletten, Kjetil, Chris I. Telmer, and Amir Yaron, "The welfare cost of business cycles revisited: Finite lives and cyclical variation in idiosyncratic risk," European Economic Review, 2001, 45 (7), 1311-1339.

Werning, Ivan, "A Reappraisal of Chamley-Judd Zero Capital Taxation Results," Working Paper, 2014. 


\section{A Misallocation in the Benchmark Economy: Details}

\section{Production environment}

Final Goods Producer. The final goods producer behaves competitively and uses labor and intermediate goods in the production of the final good:

$$
Y=Q^{\alpha} L^{1-\alpha}
$$

where $Q$ is the intermediate good aggregator given by

$$
Q=\left(\int_{i} x_{i}^{\mu} d i\right)^{1 / \mu}
$$

The problem of the final good producer can be written as

$$
\max _{Q, L} Q^{\alpha} L^{1-\alpha}-p_{q} Q-w L
$$

where $p_{q}$ is the price of the intermediate aggregate $Q$ and $w$ is the wage rate.

$$
p_{q}=\alpha Q^{\alpha-1} L^{1-\alpha}=\alpha \frac{Y}{Q}, \quad w=(1-\alpha) Q^{\alpha} L^{-\alpha}=(1-\alpha) \frac{Y}{L}
$$

The problem of the intermediate good aggregator is

$$
\max _{\left\{x_{i}\right\}} p_{q}\left(\int_{i} x_{i}^{\mu} d i\right)^{1 / \mu}-\int p_{i} x_{i} d i
$$

Taking the first order conditions, we obtain the following pricing function for intermediate good $i$

$$
p_{i}\left(x_{i}\right)=p_{q}\left(\int_{i} x_{i}^{\mu} d i\right)^{\frac{1-\mu}{\mu}} x_{i}^{\mu-1}=p_{q} Q^{1-\mu} x_{i}^{\mu-1} .
$$

Equivalently we can express the price as

$$
p(x)=\alpha x^{\mu-1} Q^{\alpha-\mu} L^{1-\alpha}=\bar{p} x^{\mu-1},
$$


which satisfies the following relation:

$$
\begin{aligned}
Q & =\left(\int_{i} x_{i}^{\mu} d i\right)^{1 / \mu} \\
Q & =\left(\int_{i}\left(\left(\frac{p_{i}\left(x_{i}\right)}{p_{q}}\right)^{\frac{1}{\mu-1}} Q\right)^{\mu} d i\right)^{1 / \mu} \\
p_{q} & =\left(\int_{i}\left(p_{i}\left(x_{i}\right)\right)^{\frac{\mu}{\mu-1}} d i\right)^{\frac{\mu-1}{\mu}}
\end{aligned}
$$

Intermediate-good producers. Producer $i$ owns the product line $i$ and produces $x_{i}$ units of intermediate good $i$ according to

$$
x_{i}=z_{i} k_{i}
$$

where $z_{i}$ is the individual $i$ 's entrepreneurial ability and $k_{i}$ is capital. Entrepreneurial ability $z_{i}$ has a permanent and a stochastic component.

Financial markets. There are financial market frictions that restrict the extent to which individuals can borrow to invest in their business. In particular, an individual with assets $a$ faces a financial constraint

$$
k \leq \vartheta\left(z_{i}\right) a
$$

where $\vartheta\left(z_{i}\right) \in[1, \infty]$. The dependence of $\vartheta$ on $z_{i}$ is to allow for the fact that more highly productive agents could potentially borrow more with the same level of capital. This is a feature that we will have in the baseline calibration and will also consider the case with $\vartheta\left(z_{i}\right)=\bar{\vartheta}$. When $\vartheta=1$ the financial constraint is extreme since the individual can only use her own assets in production. When $\vartheta=\infty$ there is no longer a financial constraint since there is no longer a restriction on the amount that an individual can borrow.

Profit maximization. The individual intermediate good producer seeks to maximize profits

$$
\pi_{i}=\max _{k_{i} \in\left(0, \vartheta\left(z_{i}\right) a_{i}\right)} p\left(z_{i} k_{i}\right) z_{i} k_{i}-(R+\delta) k_{i}
$$


The solution is to set $k_{i}$ equal to

$$
k_{i}=\min \left\{\vartheta\left(z_{i}\right) a_{i},\left(\frac{\mu \bar{p} z_{i}^{\mu}}{R+\delta}\right)^{\frac{1}{1-\mu}}\right\} .
$$

\section{Wedges and financial frictions}

In the benchmark model, the financial friction is explicitly modeled. Alternatively, distortions can be introduced in the model through a capital wedge. In that case the problem for each firm is

$$
\pi_{i}=\max _{k_{i}} p\left(z_{i} k_{i}\right) z_{i} k_{i}-\left(1+\tau_{i}^{k}\right)(R+\delta) k_{i} .
$$

The optimal level of capital is then

$$
k_{i}^{*}=\left(\frac{\mu \bar{p} z_{i}^{\mu}}{\left(1+\tau_{i}^{k}\right)(R+\delta)}\right)^{\frac{1}{1-\mu}} .
$$

Using the benchmark model, we can obtain the firm-specific capital wedges $\tau_{i}^{k}$ as

$$
\left(1+\tau_{i}^{k}\right)=\frac{\mu \bar{p}\left(z_{i} k_{i}^{*}\right)^{\mu}}{(R+\delta) k_{i}^{*}} .
$$

This solution for the optimal level of capital also allows us to compute the price and output of each intermediate good as a function of the capital wedge:

$$
\begin{aligned}
& p_{i}^{*}=\frac{1}{\mu} \frac{\left(1+\tau_{i}^{k}\right)(R+\delta)}{z_{i}} \\
& x_{i}^{*}=z_{i} k_{i}^{*}=\left(\frac{\mu \bar{p} z_{i}}{\left(1+\tau_{i}^{k}\right)(R+\delta)}\right)^{\frac{1}{1-\mu}} \propto\left(\frac{z_{i}}{1+\tau_{i}^{k}}\right)^{\frac{1}{1-\mu}}
\end{aligned}
$$

\section{Misallocation measure}

The marginal revenue product of capital for firm $i$ in sector $Q$ is

$$
M R P K_{Q, i}=\frac{\partial p\left(z_{i} k_{i}\right) z_{i} k_{i}}{\partial k_{i}}=\mu \bar{p} z_{i}^{\mu} k_{i}^{\mu-1},
$$


and firm optimization implies that

$$
M R P K_{Q, i}=\left(1+\tau_{i}^{k}\right)(R+\delta) .
$$

The average marginal revenue product of capital in the $Q$ sector is obtained by using as weights the revenue of each firm in the $Q$ sector relative to the total value of output in the $Q$ sector:

$$
\overline{M R P K_{Q}}=\int\left(M R P K_{Q, i} \frac{p_{i} x_{i}}{p_{q} Q}\right) d i
$$

Two other useful concepts are the individual firm's physical productivity

$$
T F P Q_{i}=\frac{x_{i}}{k_{i}}=z_{i},
$$

and the individual firm's revenue productivity

$$
T F P R_{Q, i}=\frac{p\left(x_{i}\right) x_{i}}{k_{i}}=\bar{p} z_{i}^{\mu} k_{i}^{\mu-1}=\frac{1}{\mu}\left(1+\tau_{i}^{k}\right)(R+\delta) .
$$

A measure of the aggregate $T F P R_{Q}$ can be obtained by noting that $T F P R_{Q, i}=$ $\frac{1}{\mu} M R P K_{Q, i}$. That implies that

$$
\overline{T F P R_{Q}}=\frac{1}{\mu} \overline{M R P K_{Q}}
$$

We can now proceed with defining the aggregate TFP in the $Q$ sector, $T F P_{Q}$, by noting that

$$
Q=T F P_{Q} \cdot K \quad \text {, where } \quad K=\int k_{i} d i .
$$

We first need to define $K$. Using the FOC of the individual firm we have:

$$
\begin{aligned}
\mu \bar{p} z_{i}^{\mu} k_{i}^{\mu} & =\left(1+\tau_{i}^{k}\right)(R+\delta) k_{i} \\
\mu \bar{p} x_{i}^{\mu-1} x_{i} & =\left(1+\tau_{i}^{k}\right)(R+\delta) k_{i} \\
\mu p_{i} x_{i} & =\left(1+\tau_{i}^{k}\right)(R+\delta) k_{i} \\
\mu p_{i} x_{i} & =M R P K_{Q, i} k_{i}
\end{aligned}
$$


which implies that

$$
k_{i}=\frac{\mu p_{i} x_{i}}{M R P K_{Q, i}} .
$$

We can use this expression to obtain an expression for the aggregate level of capital:

$$
K=\int k_{i} d i=\int \frac{\mu p_{i} x_{i}}{M R P K_{Q, i}} d i=\mu p_{q} Q \int \frac{1}{M R P K_{Q, i}} \frac{p_{i} x_{i}}{p_{q} Q} d i=\frac{\mu p_{q} Q}{\overline{M R P K_{Q}}} .
$$

Reorganizing we get:

$$
\frac{p_{q} Q}{K}=\frac{1}{\mu} \overline{M R P K_{Q}}=\overline{T F P R_{Q}}
$$

Then

$$
\begin{aligned}
T F P_{Q} & =\frac{Q}{K} \\
& =\frac{p_{q} Q}{K} \frac{1}{p_{q}} \\
& =\overline{T F P R_{Q}} \frac{1}{p_{q}} .
\end{aligned}
$$

Recall that

$$
\begin{aligned}
p_{q} & =\left(\int_{i}\left(p_{i}\left(x_{i}\right)\right)^{\frac{\mu}{\mu-1}} d i\right)^{\frac{\mu-1}{\mu}} \\
& =\left(\int_{i}\left(\frac{1}{\mu} \frac{\left(1+\tau_{i}^{k}\right)(R+\delta)}{z_{i}}\right)^{\frac{\mu}{\mu-1}} d i\right)^{\frac{\mu-1}{\mu}} \\
& =\left(\int_{i}\left(\frac{T F P R_{Q, i}}{z_{i}}\right)^{\frac{\mu}{\mu-1}} d i\right)^{\frac{\mu-1}{\mu}}
\end{aligned}
$$

Finally

$$
T F P_{Q}=\left(\int_{i}\left(z_{i} \frac{\overline{T F P R_{Q}}}{T F P R_{Q, i}}\right)^{\frac{\mu}{1-\mu}} d i\right)^{\frac{1-\mu}{\mu}}
$$

which is our measure of TFP.

If capital were allocated efficiently across firms then the marginal revenue product of 
capital would be equalized across firms. That is, if $\tau_{i}^{k}=0$ for all firms then $M R P K_{Q, i}=$ $R$. This implies that the $T F P R_{Q, i}$ of all firms would also be equalized, so that the efficient TFP level would be

$$
T F P_{Q}^{*}=\bar{z}=\left(\int_{i} z_{i}^{\frac{\mu}{1-\mu}} d i\right)^{\frac{1-\mu}{\mu}} .
$$

We can then measure the efficiency loss caused by financial frictions by the ratio of actual and efficient TFP:

$$
\frac{T F P_{Q}}{T F P_{Q}^{*}}=\left(\int_{i}\left(\frac{z_{i}}{\bar{z}} \frac{\overline{T F P R_{Q}}}{T F P R_{Q, i}}\right)^{\frac{\mu}{1-\mu}} d i\right)^{\frac{1-\mu}{\mu}}
$$

Note that this measures captures the increase in TFP regardless of the changes in total capital and aggregate prices. 